Article

\title{
Proteogenomic Analysis of Burkholderia Species Strains 25 and 46 Isolated from Uraniferous Soils Reveals Multiple Mechanisms to Cope with Uranium Stress
}

\author{
Meenakshi Agarwal ${ }^{1,+}$, Ashish Pathak ${ }^{1,+}$, Rajesh Singh Rathore ${ }^{1}$, Om Prakash ${ }^{2}$, \\ Rakesh Singh ${ }^{3}$, Rajneesh Jaswal ${ }^{1}$, John Seaman ${ }^{4}$ and Ashvini Chauhan ${ }^{1, * \mathbb{D}}$ \\ 1 Environmental Biotechnology Laboratory, School of the Environment, 1515 S. Martin Luther King Jr. Blvd., \\ Suite 305B, FSH Science Research Center, Florida A\&M University, Tallahassee, FL 32307, USA; \\ meenakshiagarwal.iitb@gmail.com (M.A.); ashishpathak72@gmail.com (A.P.); \\ rajeshrathore854@gmail.com (R.S.R.); jaswal.rajneesh@gmail.com (R.J.) \\ 2 National Centre for Microbial Resource, National Centre for Cell Science, Pune 411007, India; \\ prakas1974@gmail.com \\ 3 Translational Science Lab, College of Medicine, Florida State University, Tallahassee, FL 32304, USA; \\ rakesh.singh@med.fsu.edu \\ 4 Savannah River Ecology Laboratory, University of Georgia, Aiken, SC 29802, USA; seaman@srel.uga.edu \\ * Correspondence: ashvini.chauhan@famu.edu; Tel.: +850-412-5119; Fax: +850-561-2248 \\ $\dagger$ These authors contributed equally to this work.
}

Received: 5 November 2018; Accepted: 10 December 2018; Published: 12 December 2018

\begin{abstract}
Two Burkholderia spp. (strains SRS-25 and SRS-46) were isolated from high concentrations of uranium (U) from the U.S. Department of Energy (DOE)-managed Savannah River Site (SRS). SRS contains soil gradients that remain co-contaminated by heavy metals from previous nuclear weapons production activities. Uranium (U) is one of the dominant contaminants within the SRS impacted soils, which can be microbially transformed into less toxic forms. We established microcosms containing strains SRS-25 and SRS-46 spiked with U and evaluated the microbially-mediated depletion with concomitant genomic and proteomic analysis. Both strains showed a rapid depletion of $\mathrm{U}$; draft genome sequences revealed SRS-25 genome to be of approximately 8,152,324 bp, a G + C content of 66.5 , containing a total 7604 coding sequences with 77 total RNA genes. Similarly, strain SRS-46 contained a genome size of $8,587,429$ bp with a $G+C$ content of $67.1,7895$ coding sequences, with 73 total RNA genes, respectively. An in-depth, genome-wide comparisons between strains 25,46 and a previously isolated strain from our research (Burkholderia sp. strain SRS-W-2-2016), revealed a common pool of 3128 genes; many were found to be homologues to previously characterized metal resistance genes (e.g., for cadmium, cobalt, and zinc), as well as for transporter, stress/detoxification, cytochromes, and drug resistance functions. Furthermore, proteomic analysis of strains with or without U stress, revealed the increased expression of 34 proteins from strain SRS- 25 and 52 proteins from strain SRS-46; similar to the genomic analyses, many of these proteins have previously been shown to function in stress response, DNA repair, protein biosynthesis and metabolism. Overall, this comparative proteogenomics study confirms the repertoire of metabolic and stress response functions likely rendering the ecological competitiveness to the isolated strains for colonization and survival in the heavy metals contaminated SRS soil habitat.
\end{abstract}

Keywords: genomics; proteomics; uranium; Burkholderia 


\section{Introduction}

Savannah River Site (SRS) located in Aiken, SC, functioned as a nuclear materials production facility for the U.S. Department of Energy (DOE), where metal-clad uranium (U) targets were used in the production of plutonium [1]. From 1954 to 1982, SRS wastewater originating from the metal plating and fabrication processes was released directly into Tims Branch, a second-order stream. Because of these activities, large quantities of $U$ (depleted as well as naturally-occurring) was released and deposited into stream sediments and an abandoned farm pond - the Steeds Pond, that served as a natural settling basin along Tims Branch [1,2]. Although contaminant distribution is heterogeneous in the Steeds Pond sediments, U concentration is found upwards of $1000 \mathrm{mg} / \mathrm{kg}$ [2]. To gauge in-situ remediation (natural attenuation) and recommend appropriate strategies for the remediation of contaminated SRS ecosystems, it is necessary to obtain a deeper understanding of the mechanisms possessed by the native soil microbiota to resist metals and radionuclides. In fact, microorganisms exposed to the contaminant stresses not only have the unparalleled ability to survive in radionuclide contaminated environments but also potentially reduce toxicity of U [3-5]. For example, $90 \%$ of bacteria belonging to Firmicutes, Gammaproteobacteria, Actinobacteria, Bacteroidetes and Betaproteobacteria were found to resist high uranium concentration of up to $4 \mathrm{mM}$ from a uranium mining site in Domiastat, India [6]. Kulkarni et al. isolated two phosphatase producing bacteria- E. coli and Deinococcus radiodurans, and showed that both grew in the presence of up to $20 \mathrm{mM}$ uranium [7]. Evolutionary mechanisms that include bioreduction, biosorption, biomineralization, and bioaccumulation are utilized by environmental microbiota to persist in uraniferous niches [4]. Among these mechanisms, $\mathrm{U}$ biomineralization has recently garnered significant interest because this bioremediative process entails formation of $\mathrm{U}(\mathrm{VI})$ phosphate minerals as a function of microbial enzymatic activities and consequently, $\mathrm{U}$ is sequestered as stable solid mineral phases within the environmental matrices $[8,9]$. However, genomic mechanisms underpinning $U$ transformation into the less-mobile and less-toxic forms, such as a U mineral, continue to remain understudied and hence unclear, especially for the SRS uraniferous soils.

Soil samples for this study were collected from site 101 located within the Tims Branch system. At this site, $U$ concentrations are typically present between 700-800 ppm [5], which is a high concentration based on a previously reported criteria [10]. Therefore, the historical contamination of the SRS site presents with an opportunity to study genome-enabled mechanisms recruited by the SRS-native microorganisms facilitating their survival in co-contaminated environments. In fact, the stress posed by environmental contaminants facilitate recruitment of genes by horizontal gene transfer mechanisms that enable the microbial cells to not only resist but also bioremediate the contaminants, mostly by the synthesis of proteins for cellular survival [11]. Some examples of such cellular and genomic-mechanisms include membrane-bound efflux pumps, presence of metal resistant genes, detoxification genes, and biosorption/bioaccumulation of the contaminant at or within the bacterial cell membrane [12].

To further understand environmentally-relevant molecular mechanisms that underpin microbial survival in radionuclide and heavy metal-rich ecosystems, we recently isolated several bacterial strains in the presence of high uranium concentrations [13]. 16S rRNA gene sequence based analysis revealed that the isolated strains mainly belonged to Burkholderia spp. and Arthrobacter spp., these genera have been previously demonstrated to serve as bioindicators of environmental contamination as well as agents of bioremediation, especially U [14]. Notably, Burkholderia spp., have also been shown by others to successfully thrive in habitats that pose extreme environmental stresses, including uranium-rich ecosystems. For example, Burkholderia-like microorganisms comprised a significant proportion of the soil microbiota at the Integrated Field-Scale Subsurface Research Challenge Site (IFRC), Oak Ridge, Tennessee [15] as well as Rifle, Colorado [16]. The intrinsic ability of Burkholderiales to dominate uraniferous habitats is not entirely surprising, owing in part to their repertoire of metabolic abilities, attributed to the large, multi-replicon genome, conferring genome plasticity and metabolic versatility [17], respectively. Adding to this knowledge on Burkholderiales, our recent 
study also showed genome-enabled mechanisms possessed by another soil isolate-Burkholderia sp. strain SRS-W-2-2016, that colonized the heavy metal-rich SRS soil habitat [13]. From these studies, it was evident that Burkholderia spp. recruited a suite of genomic traits to facilitate survival in radionuclide and metal-contaminated habitats. Such traits included several gene homologues previously demonstrated to render resistance against heavy metals and radionuclides, including a suite of substrate-binding proteins, permeases, transport regulators, and efflux pumps. These likely work in concert to potentially detoxify toxic metals and thus facilitate the natural attenuation of contaminants within the SRS-impacted ecosystem. Another interesting genomic trait that our previous study identified in the Burkholderia sp. strain SRS-W-2-2016 was the presence of several genomic islands (GEIs). Notably, bacterial genomes not only consist of the "core" set of genes that provide for essential metabolic functions but can also harbor genes acquired from the bacterium's native environment via horizontal gene transfer (HGT) mechanisms. These "foreign" genes, typically occurring as orthologous genomic blocks, called genomic islands [18], can provide several beneficial traits to the host bacterium, including environmental adaptations and genomic plasticity. In fact, GEIs have been functionally classified into the following four broad categories: pathogenicity islands (PAIs), harboring virulence genes; metabolic islands (MIs), genes that code for secondary metabolite biosynthesis; resistance islands (RIs), genes that typically provide resistance against antibiotics; and symbiotic islands (SIs), those genes that facilitate symbiotic associations of the host with other micro- and macroorganisms, respectively. Thus, genome-wide mining of environmentally relevant microorganisms (e.g., Burkholderiales), can provide a broader understanding on the basis of metal-Burkholderia interactions, which can form the basis of targeted management of desirable microbial traits, including bioremediation, resulting in better stewardship of nuclear-legacy contaminated environments.

Note, however that, to obtain a holistic understanding at the cellular level of bacteria, against uranium, analysis that combines the genomics and proteomics dataset, termed as proteogenomics, can be a very powerful approach. Such an approach has the ability to provide a unique peek into the uranium-microbe interaction(s), including other relevant metabolic and functional traits possessed by the bacteria under study. Despite this, only a few studies are available on the impacts of $U$ stress at the proteomic level, especially for aerobic microbiota. To further advance on this aspect of metal-microbe interactions, Gallois and coworkers recently integrated the genomics and proteomics data of Microbacterium oleivorans A9, a uranium-tolerant actinobacteria isolated from near the Chernobyl nuclear power plant, when grown in the presence or absence of uranyl nitrate [19]. This study revealed 1532 proteins and specifically, 591 proteins with significant differences in abundances when gown with or without uranium. Under the influence of U(VI) exposure, Yung et al., identified a phytase enzyme and an ABC transporter to be upregulated in Caulobacter crescentus [20], which can tolerate high concentrations of $U$ [21]. Therefore, the objective of this study was to obtain genomics and high-throughput proteomics data on strains SRS-25 and SRS-46, grown with and without uranium, thus forming a strong basis of our understanding on the underpinnings of U-Burkholderia interactions, which to our understanding, has not been previously demonstrated. Such studies can lead to the identification of gene-protein targets to not only gauge but predict the trajectory of uranium bioremediation in historically U-contaminated environments.

\section{Material and Methods}

\subsection{Isolation and $U$ Resistance Studies on Strains SRS-25 and SRS-46}

Burkholderia sp. 25 and 46 were isolated from uraniferous SRS soils collected from the Tims Branch/Steeds Pond area. Briefly, soil samples were serially diluted and $100 \mu \mathrm{L}$ of this slurry was plated onto LB agar supplemented with uranyl nitrate at a concentration of $4.2 \mathrm{mM}$; this mimics the uranium concentration present in-situ within the SRS soils [22]. Cells that grew on LB + U media were also screened on Tryptose Phosphate Methyl Green (TPMG) media to screen for phosphatase-based uranium biomineralization activity as shown before [22,23]. Two of the most robustly growing isolates 
on uranium with phosphatase positive activity on TPMG media-named as strains \#25 and \#46 were selected for further physiological and proteogenomic studies.

Resistance of strains 25 and 46 against different concentrations of uranium was evaluated by growth, which was analyzed using the Bioscreen C system (Growth Curves USA, Piscataway, NJ, USA), as reported previously [22]. Briefly, $4 \mathrm{M}$ media [24] (modified with the addition of $0.04 \%$ yeast extract) was supplemented with $U$ ranging from $0-5000 \mu \mathrm{M}$. The assay was run using the honeycomb Bioscreen C plates containing $290 \mu \mathrm{L}$ medium and $10 \mu \mathrm{L}$ of the inoculum, which was grown overnight to an $\mathrm{OD}_{600}$ of $0.3 \pm 0.05$. The instrument was programmed to perform regular shaking and capture $\mathrm{OD}_{600}$ at increments of every $3 \mathrm{~h}$ for $68 \mathrm{~h}$; these experiments were run in triplicates and averaged values are reported.

\subsection{Uranium Depletion by Strains SRS-25 and SRS-46}

To determine $U$ remediation potential of Burkholderia sp. strains 25 and 46, microcosms were established in $4 \mathrm{M}$ media supplemented with $1000 \mu \mathrm{M} \mathrm{U}$ to which were then added overnight grown cultures to a final $\mathrm{OD}_{600}$ of $0.05 \pm 0.01$, as reported recently [13,22]. Briefly, flasks were incubated at $30{ }^{\circ} \mathrm{C}$ and $120 \mathrm{rpm}$ and samples were taken every $24 \mathrm{~h}$ for 2 days. The samples were centrifuged, and supernatant was acidified using $\mathrm{HNO}_{3}$ to a final concentration of $2 \%$. Uranium depletion in the supernatants was measured by inductively coupled plasma-mass spectrometry (ICP-MS) on a NexIon 300 (Perkin Elmer, Waltham, MA, USA) in accordance with the quality assurance (QA) and quality control (QC) protocols of EPA method 6020B (USEPA, 2014; Method 6020B, Rev. 2. Inductively coupled plasma-mass spectrometry (ICP-MS), Office of Solid Waste, Washington, DC, USA). Cell pellets were saved immediately in $-80^{\circ} \mathrm{C}$ collected at time 0 , day 1 and day 2 for proteomics studies.

\subsection{Genomic Characterization of Strains SRS-25 and SRS-46}

Genomic DNA from strains SRS-25 and SRS-46 was extracted and prepared for sequencing on an Illumina HiSeq2000 instrument, as described previously [13]. De novo assembly of the raw reads was performed with the SPAdes assembler [25] using default settings. Assembly coverage statistics were computed by mapping raw reads to the assembled genome using bowtie2 [26]. Specifically, we determined a coverage filter for the contigs from the distribution of coverage levels across the assembly. First, contigs were ordered by coverage, and cumulative assembly length was computed across all contigs. Coverage level at $50 \%$ of the total cumulative assembly length was determined and half of that coverage level was selected as a coverage filter. The remaining reads were aligned with nucmer [25] against the closest reference sequence from NCBI (determined by a BLAST of the 16S rRNA sequence): accession numbers CP002013.1, CP002014.1, and NC_014119.1 for chromosomes 1, 2, and 3. All contigs, for each strain, were aligned to these references, and the optimal contig ordering and orientation to most closely match the reference was determined using mummerplot [25] with layout specified. Contigs were then reordered and reversed as needed to match the ordering determined by mummerplot. Circular genomic maps were generated using the CGView Comparison Tool [27].

The genomes, with a coverage of 250x, were then annotated and genes predicted by IMG/er [28], RAST [29] and NCBI's Prokaryotic Genomes Automatic Annotation Pipeline (PGAAP), version 2.0. Genome-based phylogenetic tree of the strains were constructed using the One Codex database platform [30], which generates taxonomic classification of nucleotide reads by assessing for exact k-mer matches against their database of bacterial, viral, and fungal genomes as well as the National Center for Biotechnology Information's (NCBI) Reference Sequence Database. Comparative genomics of strains SRS-25 and SRS-46 relative to closest taxonomic relatives was performed by EDGAR [31].

\subsection{Protein Extraction and Separation}

Protein extraction and mass spectrometry were performed at Translational Science Laboratory, Florida State University. Cells (50) mg were collected from treated (with uranyl nitrate) and untreated microcosms from the day 1 time point, which coincided with the maximum depletion of uranium, 
followed by resuspension in $500 \mu \mathrm{L}$ of SDT lysis buffer (4\% SDS, $20 \mathrm{mM}$ Tris- $\mathrm{HCl}$ (pH 8.6), $50 \mathrm{mM}$ DTT, protease inhibitor tablets (ThermoFisher Scientific, Gainesville, FL, USA), and MS grade water). Suspended cells were frozen and thawed three times in liquid nitrogen and at $95{ }^{\circ} \mathrm{C}$ hot bath respectively for $15 \mathrm{~min}$. Approximtely $50 \mathrm{mg}$ of glass beads (G8772-Sigma 425-600 $\mu \mathrm{m}$ ) were added to the cell suspension and subjected to 10 cycles of bead beating for each $45 \mathrm{~s}$ cycle and $3 \mathrm{~min}$ ice interval between every cycle. Lysed cells were centrifuged at 16,000 $\mathrm{g}$ for $15 \mathrm{~min}$ and supernatant was collected in the fresh tube. Total protein was quantified by Pierce ${ }^{\mathrm{TM}}$ BCA Protein Assay kit (Thermo Scientific, Waltham, MA, USA) using a Nanodrop Spectrophotometer (Thermo Scientific, Waltham, MA, USA).

For protein separation on SDS-PAGE, $30 \mu \mathrm{g}$ of protein was loaded in precast-mini Protean $\mathrm{R}$ TFX ${ }^{\mathrm{TM}}$ Gels (4-20\%, 10 well combs, $50 \mathrm{~mL}$ BioRad, Hercules, CA, USA) and stained with Coomassie blue dye. Samples were fractionated by cutting the gel lanes into four sections from destained gel. Individual gel pieces were kept into a separate eppendorf tubes. In-gel digest was performed using ProteoExtract All-in-One Trypsin Digestion Kit (Cat. No. 650212 Calbiochem, San Diego, CA, USA) according to manufacturer's instructions. Briefly, carefully excised gel pieces were destained with wash buffer, dried at $95^{\circ} \mathrm{C}$ for $15 \mathrm{~min}$. Gels were rehydrated with digest buffer, reduced using the reducing agent for $10 \mathrm{~min}$ at $37^{\circ} \mathrm{C}$. Samples were cooled to RT and then blocked using blocking reagent for $10 \mathrm{~min}$ at room temperature. Trypsin at a final concentration of $8 \mathrm{ng} / \mu \mathrm{L}$ was added and incubated for $2 \mathrm{~h}$ at $37^{\circ} \mathrm{C}$ with shaking. Peptides were eluted in $50 \mu \mathrm{L} 0.1 \%$ FA and run on LCMS.

\subsection{Mass Spectrometry and Protein Identification}

An externally calibrated Thermo Q Exactive HF (high-resolution electrospray tandem mass spectrometer) was used in conjunction with Dionex UltiMate3000 RSLC nano System (Thermo Scientific, Waltham, MA, USA). A $5 \mu \mathrm{L}$ sample was aspirated into a $50 \mu \mathrm{L}$ loop and loaded onto the trap column (Thermo $\mu$-Precolumn $5 \mathrm{~mm}$, with nanoViper tubing $30 \mu \mathrm{m}$ i.d. $\times 10 \mathrm{~cm}$ ). The flow rate was set to $300 \mathrm{~nL} / \mathrm{min}$ for separation on the analytical column (Acclaim pepmap RSLC 75 $\mu \mathrm{M} \times 15 \mathrm{~cm}$ nanoviper, Thermo Scientific, Waltham, MA, USA). Mobile phase A was composed of $99.9 \mathrm{H}_{2} \mathrm{O}$ (EMD Omni Solvent, Millipore Sigman, Austin, TX, USA), and 0.1\% formic acid and mobile phase B was composed of $99.9 \% \mathrm{ACN}$, and $0.1 \%$ formic acid. A 60 min linear gradient from $3 \%$ to $45 \%$ B was performed. The LC eluent was directly nanosprayed into Q Exactive HF mass-spectrometer (Thermo Scientific). During the chromatographic separation, the Q-Exactive HF was operated in a data-dependent mode and under direct control of the Thermo Excalibur 3.1.66 (Thermo Scientific). The MS data were acquired using the following parameters: 20 data-dependent collisional-induced-dissociation (CID) MS/MS scans per full scan (350 to $1700 \mathrm{~m} / \mathrm{z}$ ) at 60,000 resolution. MS2 were acquired in centroid mode at 15,000 resolution. Ions with single charge or charges more than 7 as well as unassigned charge were excluded. A $15 \mathrm{~s}$ dynamic exclusion window was used. All measurements were performed at RT and three technical replicates were run for each sample. The raw files were analyzed using Proteome Discoverer (version 2.0, ThermoFisher Scientific, Gainesville, FL, USA) software package with SequestHT and Mascot search nodes using species specific tremble fasta database and the Percolator peptide validator. The resulting msf files were further analyzed by the proteome validator software 'Scaffold version 4.4' (Portland, OR, USA).

\subsection{Statistical Analysis}

Statistical analysis on the genomic data was performed using the embedded tools within the pipelines used for comparative genomics. The proteomics data sets were combined as a union, imputing abundance values of 0 if a protein was found in one data set but not in the other. Ordination analyses were then performed using non-metric multidimensional scaling (NMDS) with the Bray-Curtis similarity coefficient in Primer-E version 6.1.13 and PERMANOVA version 1.0.3 (Albany, Auckland, New Zealand). Also computed were the $\log 2$ fold-change between control and uranium samples in each genome, and the top 50 proteins based on the maximum log2 fold-change in either 
genome were plotted as a heatmap.A complete-linkage hierarchical clustering on proteins and across samples were run and plotted as heatmaps.

\subsection{Genomic and Proteomic Data Accession Numbers}

The Whole Genome Shotgun of Burkholderia species reported in this study have been deposited at DDBJ/ENA/GenBank under BioSample: SAMN08567921 (SRS-25); SAMN08567954 (SRS-46) and SAMN06141630 (SRS-W-2-2016). The mass spectrometry proteomics data have been deposited to the ProteomeXchange Consortium via the PRIDE [32] repository with the dataset identifier PXD011367 and 10.6019/PXD011367.

\section{Results}

\subsection{Depletion of Uranium by Strains SRS-25 and SRS-46}

Two robustly U-resistant strains, named SRS-25 and SRS 46, were isolated from a uraniferous Savannah River Site (SRS) soils. The phosphatase-based U biomineralization activity of these strains was checked on TPMG media as previously shown [22,23], which showed a phosphatase positive response (please see graphical abstract). To determine the U resistance potential of strains SRS-25 and SRS-46 different concentrations of $U$ were supplemented in $4 \mathrm{M}$ media and growth results are presented in Figure 1A,B. Strains SRS-25 and 46 could resist up to $5000 \mu \mathrm{M}$ of U, which is the typical concentrations of $U$ in the sampling location [13], although with an increased lag phase. Rapid growth occurred at the lower concentration of $1000 \mu \mathrm{M} \mathrm{U}$ and stationary phase was reached in $24 \mathrm{~h}$ (Figure 1A,B). This suggested that $1000 \mu \mathrm{M}$ of $\mathrm{U}$ is likely one of the best concentrations to run proteomic analysis on strains SRS-25 and SRS-46, respectively.

The above resistance abilities of strains SRS-25 and SRS-46 to U were further confirmed by ICP-MS analysis on microcosms established with $1000 \mu \mathrm{M}$ U followed by quantifying the depletion of amended $U$; these results are shown in Figure 1C. Notably, the concentration of $U$ rapidly declined in merely $24 \mathrm{~h}$; strongly suggesting that both strains possessed the ability to rapidly biotransform and/or bioremediate U. However, in both strains, more specifically in strain 25 , uranium started to reappear after being completely depleted from the supernatant (Figure 1C); it is likely that some fraction of uranium was biosorbed onto the cellular surface after immediate exposure to uranium and eventually the cellular-bound uranium began to desorb into the supernatant as a function of time. It could also be that initially $\mathrm{U}$ was transported into the cells and by $33 \mathrm{~h}$ post-exposure, efflux pumps started to dump some of this uranium extracellularly.

A

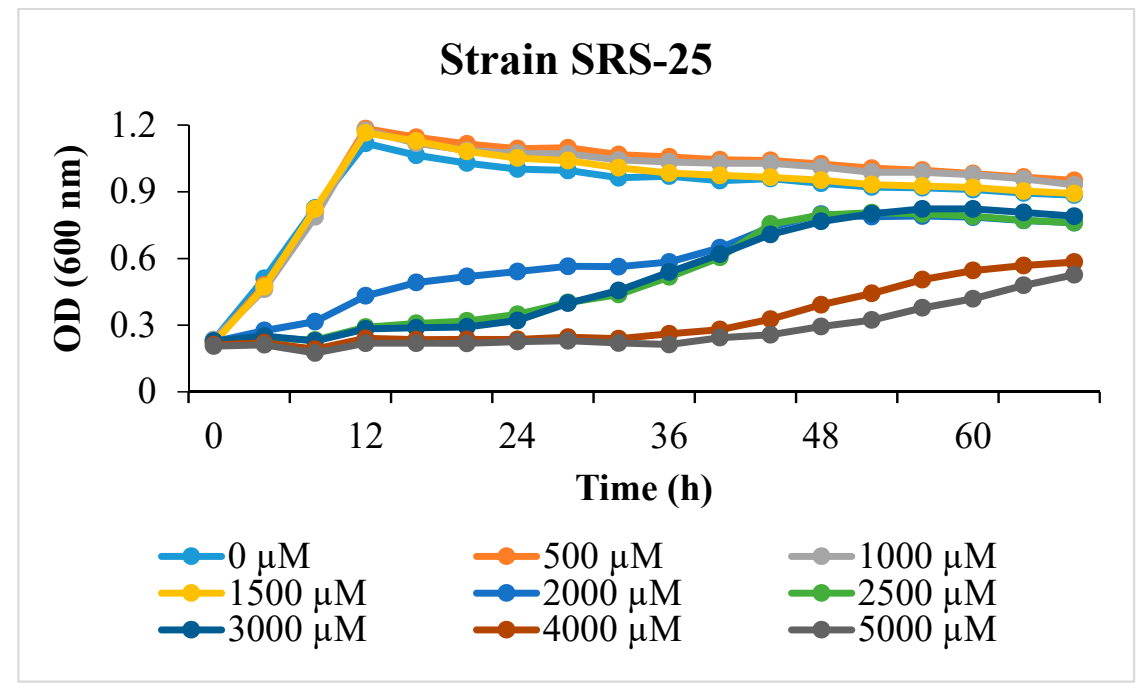

Figure 1. Cont. 
B

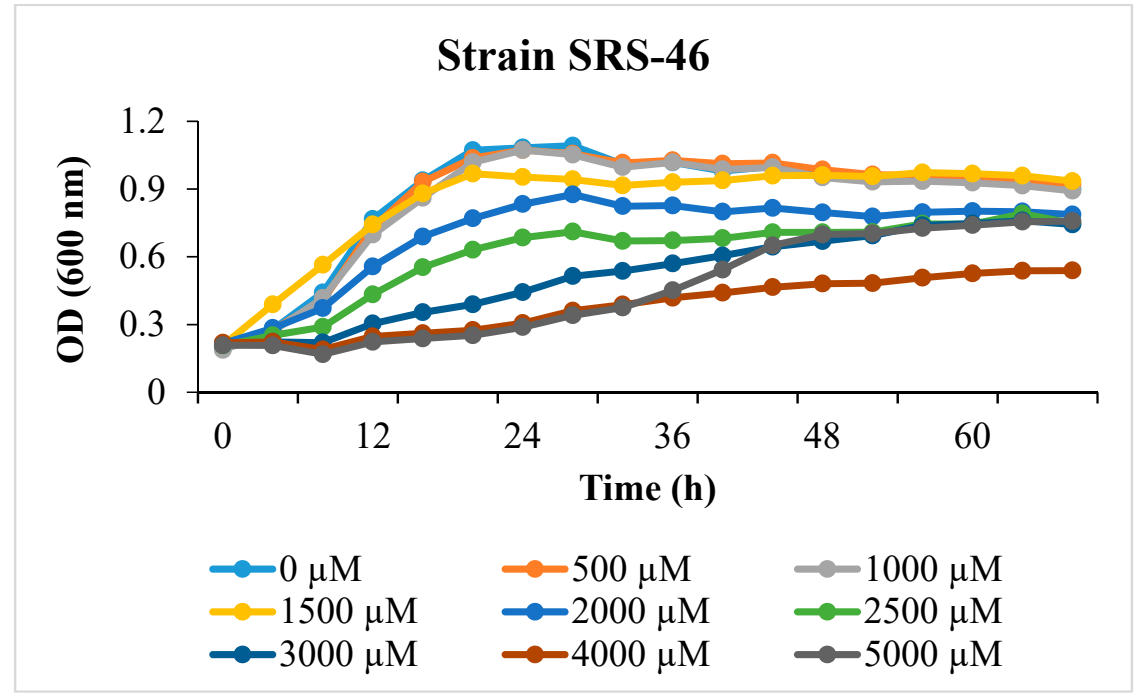

C

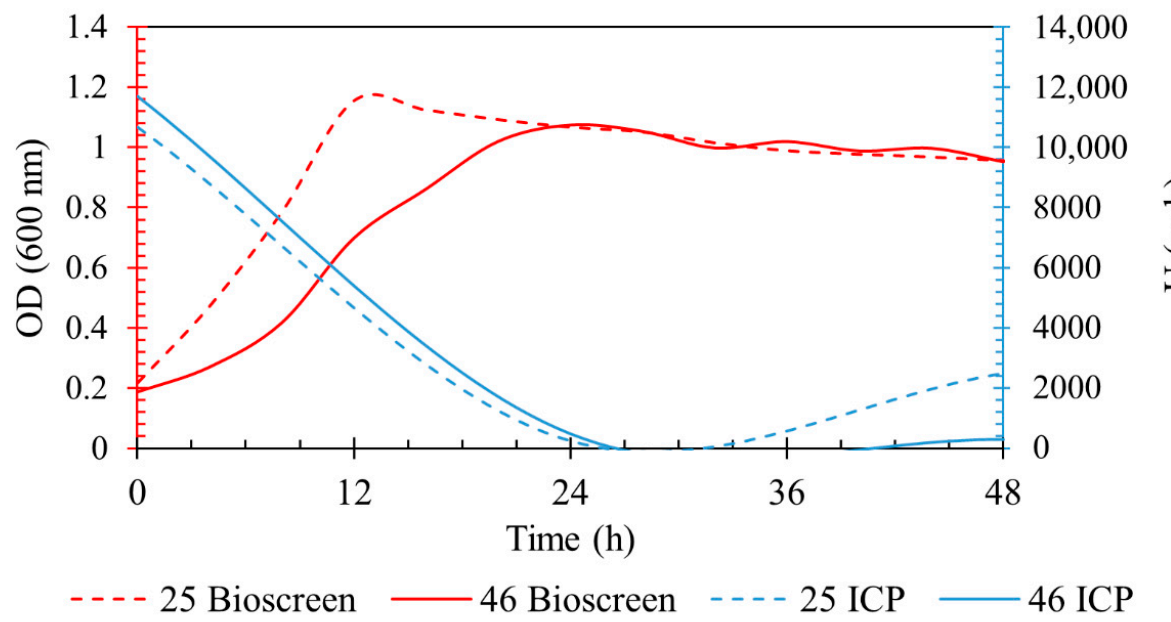

Figure 1. Shown is the resistance abilities of Burkholderia sp. SRS-25 (A) and SRS-46 (B) at uranium concentration ranging from 0 to $5000 \mu \mathrm{M}$. Also shown is the growth (Bioscreen $\mathrm{C}$ ) and concomitant depletion of uranium evaluated by inductively coupled plasma-mass spectrometry (ICP-MS) in microcosms spiked with $1000 \mu \mathrm{M}$ uranium (C); red lines depict growth at $\mathrm{OD}_{600}$ strain along with depletion of uranium shown in blue color, respectively.

\subsection{Genome-Centric Evaluation to Identify Metal Resistance Basis of Isolated Strains}

The whole genome sequence of strain SRS-25 assembled into 66 contigs with an N50 of 285073 and 23 contigs with an N50 of 662813 for SRS-46, respectively. As shown in Figure 2A,B, strain SRS-25 possessed a genome of approximately 8,152,324 bp, a G + C content of 66.5, containing a total 7604 coding sequences with 77 total RNA genes. Similarly, strain SRS-46 was predicted to be approximately $8,587,429$ with a G + C content of 67.1 and contained 7895 coding sequences, with 73 total RNA genes, respectively. The genomic traits of strains SRS-25 and SRS-46 stated above are in line with the Burkholderia genomes, which are known to be variable in size ranging from $2.4 \mathrm{Mb}$ (Ca. Burkholderia schumannianae UZHbot8) [33] to $11.5 \mathrm{Mb}$ (Burkholderia terrae BS001), are characterized by a high G $+\mathrm{C}$ content (62-68 mol\%) and consist of multiple replicons [34]. To further infer the genome-wide taxonomic affiliation of strains SRS-25 and SRS-46, EDGAR analysis was run (Figure 3). A genome-wide phylogenetic tree from this analysis revealed that both these strains cluster within the Burkholderia cepacia complex (Bcc); a group of approximately 20 closely related species [35]; many isolates have demonstrated commercial potential as biological control agents of plant pathogens, bioremediation of 
recalcitrant xenobiotics and plant growth promoting abilities. Moreover, the Bcc group is ubiquitously found ranging from soils, aquatic habitats, and plant rhizosphere niches, associated with humans, animals and also pathogens in hospital environments. Bcc species are extremely versatile metabolically by utilizing more than 200 organic compounds, are resistant to multiple antibiotics and even fix atmospheric nitrogen $\left(\mathrm{N}_{2}\right)$. Strains from the Bcc group possess large-plastic genomes represented by multiple chromosomes- typically ranging from 2 to 4 replicons, which contributes to ecological competitiveness of the Bcc group.
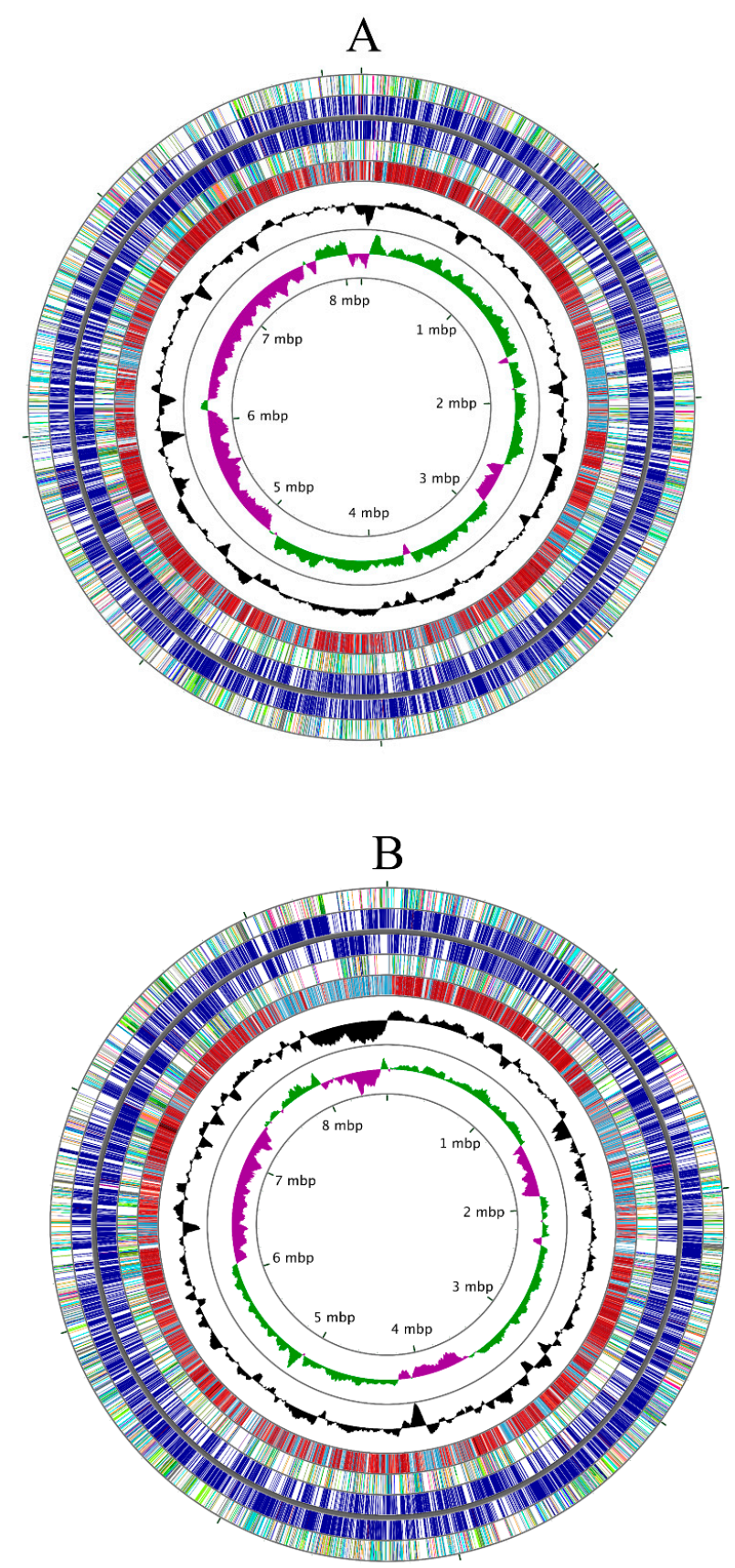

\begin{tabular}{|l}
\hline A COG \\
B COG \\
J COG \\
K COG \\
L COG \\
D COG \\
O COG \\
M COG \\
N COG \\
P COG \\
T COG \\
U COG \\
V COG \\
W COG \\
Y COG \\
Z COG \\
C COG \\
C COG \\
E COG \\
F COG \\
H COG \\
I COG \\
Q COG \\
R COG \\
S COG \\
Unknown COG \\
CDS \\
tRNA \\
rRNA \\
Other \\
BLAST hit $=100 \%$ identical \\
BLAST hit $>=90 \%$ identical \\
BLAST hit $>=80 \%$ identica \\
BLAST hit $>=70 \%$ identical \\
BLAST hit $>=60 \%$ identicaa \\
BLAST hit $>=50 \%$ identical \\
BLAST hit $>=40 \%$ identica \\
BLAST hit $>=30 \%$ identical \\
BLAST hit $>=20 \%$ identica \\
BLAST hit $>=10 \%$ identical \\
BLAST hit $>=0 \%$ identical \\
GC content \\
GC skew + \\
GC skew- \\
\end{tabular}

Figure 2. Shown are circular genomic maps of Burkholderia sp. strain SRS-25 (A) and SRS-46 (B). The first (outermost) and fourth rings depict COG categories of protein coding genes on the forward and reverse strands; the second and third rings show the locations of protein coding, tRNA, and rRNA genes on the forward and reverse strands; the fifth ring displays regions of similarity detected using BLAST (E-value $=0.0001$ ) between strain SRS-25 or SRS-46 coding sequence translations and those from the genome of Burkholderia multivorans ATCC 17616 (accessions CP000868, CP000869, CP000870, 
CP000871). Regions of similarity are colored based on the percent identity between the aligned proteins. The black plot depicts GC content with the peaks extending towards the outside of the circle representing GC content above the genome average, whereas those extending towards the center mark segments with GC content lower than the genome average. The innermost plot depicts GC skew. Both base composition plots were generated using a sliding window of 50,000 nt.

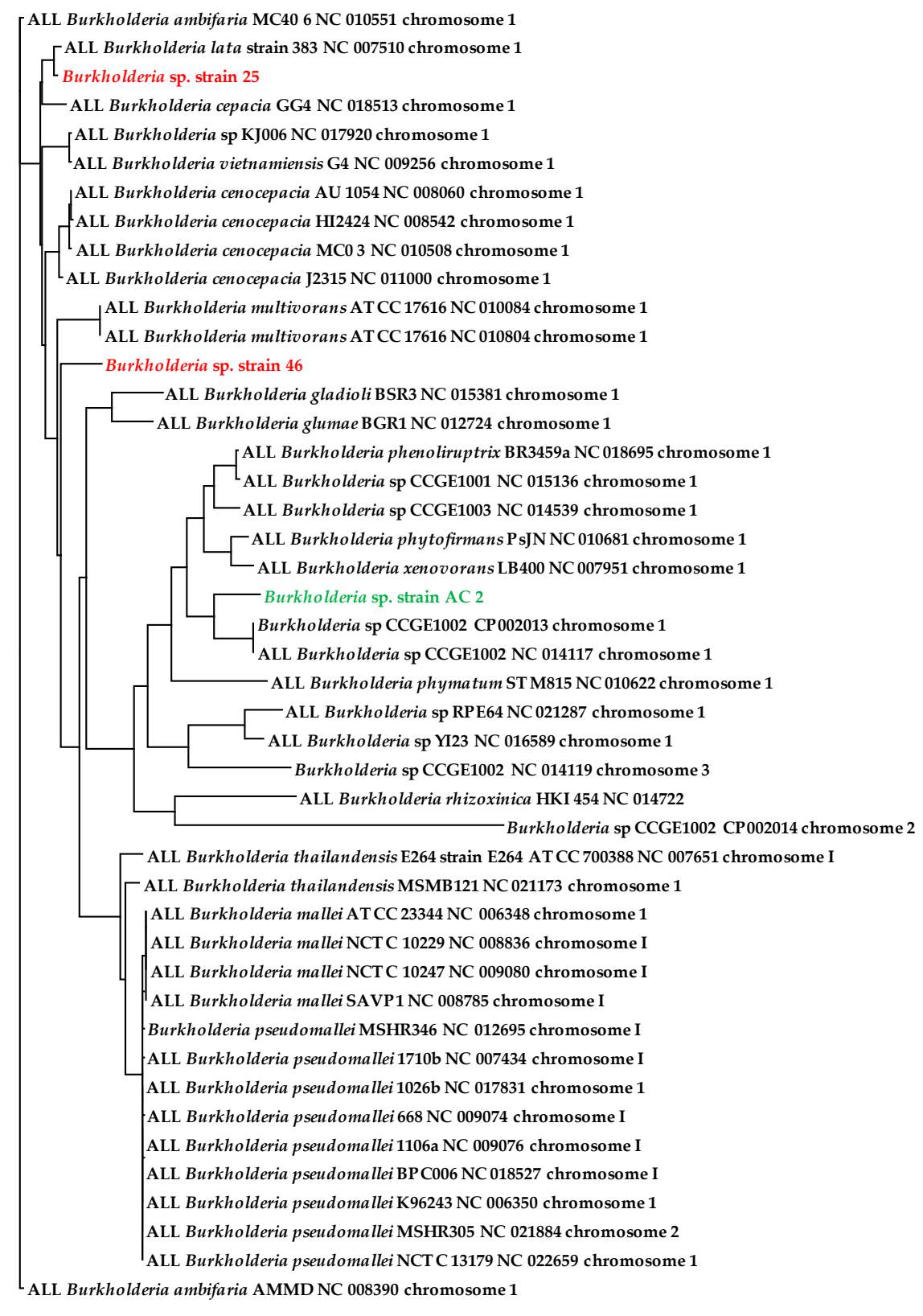

$\stackrel{\mapsto}{0.02}$

Figure 3. Depicted is the genome-wide phylogenetic tree of Burkholderia species reported in this study. Tree for 45 genomes was built using the EDGAR pipeline, out of a core of 2 genes per genome, 90 in total. The core consists of 1155 AA-residues/ bp per genome, 51,975 in total. Shown in red color are the two Burkholderia species isolated from SRS soils reported in this study, and the one shown in green color was obtained from a previous study.

Notably, the EDGAR analysis also revealed that strains 25, 46 and a previously isolated strain from our research (Burkholderia sp. strain SRS-W-2-2016), share a common pool of 3128 genes (Figure 4A). 
Moreover, several distinctive genes, shown in parenthesis, were also identified from each of the closest taxonomic relatives of the SRS strains (Figure 4B): Burkholderia lata strain 383 (1308); B. multivorans (1056); B. sp. strain SRS-25 (826), B. sp. strain SRS-46 (1749) and B. sp. strain SRS-W-2-2016 (2580), respectively. Among the suite of 3128 genes common only to the SRS strains, we found several metal resistant gene homologues as shown in Table 1. Of specific interest were genes that encoded metal resistance proteins (e.g., for cadmium, cobalt, and zinc), transporter proteins, stress proteins, cytochromes, and drug resistance, respectively.
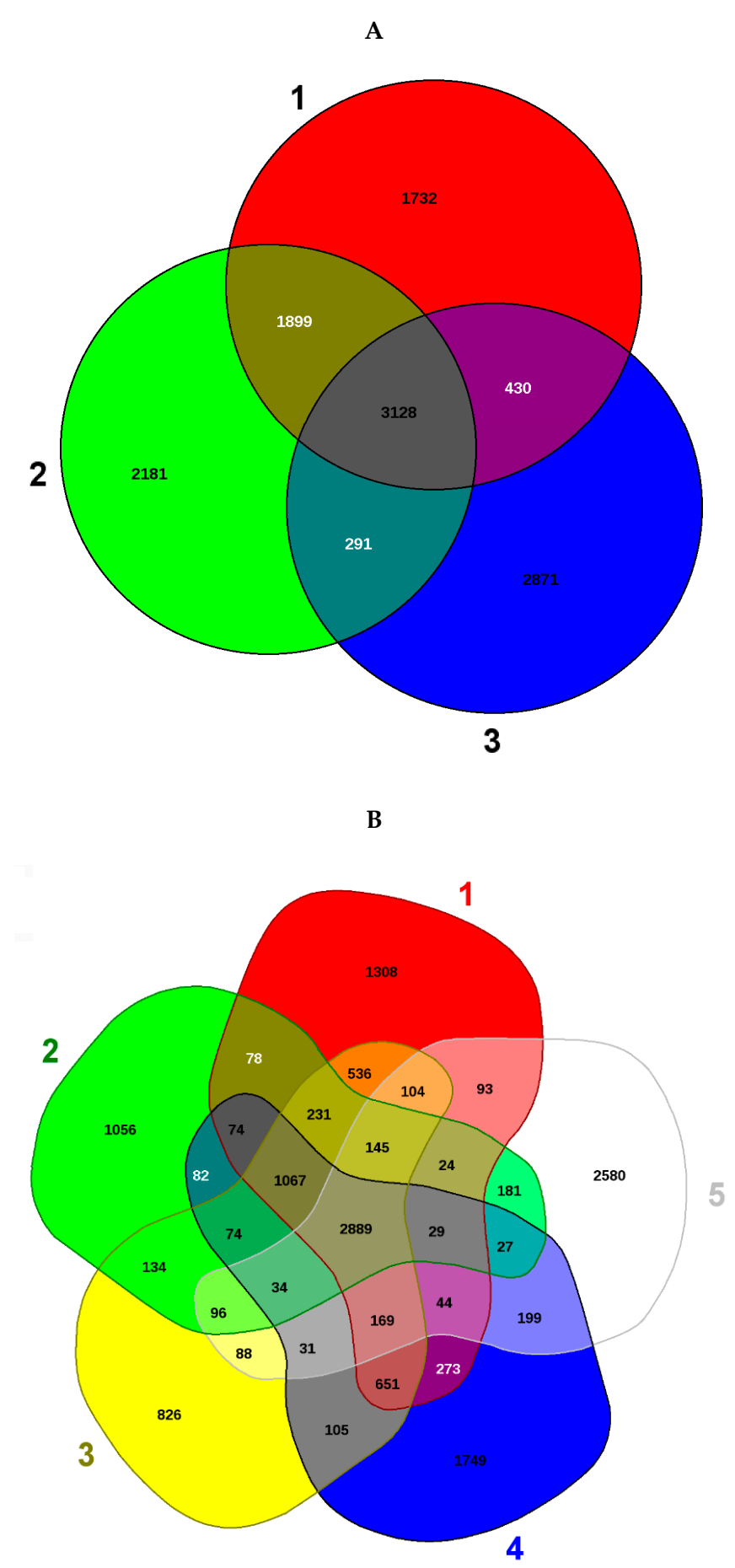

Figure 4. Shown are the whole-genome sequence-based Venn diagrams generated by the EDGAR pipeline revealing strains SRS-25 and 46 along with a previously isolated strain from our research (Burkholderia sp. strain SRS-W-2-2016). These isolates share a common pool of 3128 genes (A); Venn 
diagram sectors belong to 1 (red), Strain SRS-25; 2, SRS-46 (green) and 3, SRS-W-2-2016 (blue), respectively. Shown in $(\mathbf{B})$ are several distinctive genes identified when comparisons were run between the two closest taxonomic relatives: Burkholderia lata strain 383 (sector 1, red); B. multivorans (sector 2, green); strain SRS-25 (sector 3, yellow); strain SRS-46 (sector 4, blue) and SRS-W-2-2016 (sector 5, white). The core genomes are shown in the centered gray area.

Table 1. Shown are the EDGAR identified core set of gene homologues common between Burkholderia sp. strain SRS-25, strain SRS-46 and SRS-W-2-2016 that likely perform a biodegradative or metal resistance function.

\begin{tabular}{|c|c|}
\hline Category & Gene Homologue \\
\hline Transporter proteins & $\begin{array}{c}\text { Proline/Betaine transporter } \\
\text { MFS-type transporter YhjX, YcaD } \\
\text { Phospholipid ABC transporter permease protein } \\
\text { ABC transporter ATP-binding protein YbhF, YheS } \\
\text { Cystine inner membrane transporter } \\
\text { Hemolysin transporter protein ShlB precursor } \\
\text { Divalent metal cation transporter MntH } \\
\text { Inner membrane ABC transporter permease protein } \\
\text { Riboflavin transporter } \\
\text { Dicarboxylic acid transporter DauA } \\
\text { Inner membrane transporter yiJE, YedA, YnfM } \\
\text { Sulfoacetate transporter SauU } \\
\text { Citrate transporter } \\
\text { Lysophospholipid transporter LplT } \\
\text { Niacin/nicotinamide transporter NaiP } \\
\text { (3-hydroxy-phenyl) propionate transporter } \\
\text { Tartrate transporter } \\
\text { H(+)/Cl(-) exchange transporter ClcA } \\
\text { D-galactonate transporter } \\
\text { Low-affinity inorganic phosphate transporter 1 } \\
\text { L-galactonate (Hexuronate) transporter } \\
\text { Heme/hemopexin transporter protein HuxB precursor } \\
\text { Sialic acid transporter } \\
\text { Amino-acid permease protein YxeN } \\
\text { Glutamate/aspartate transporter permease protein } \\
\text { Fluoride ion transporter CrcB } \\
\text { Sialic acid transporter } \\
\text { Fe (3+) ions import ATP-binding protein FbpC } \\
\text { 4-hydroxybenzoate transporter PcaK } \\
\text { Glucarate transporter } \\
\text { Efflux pump membrane transporter BepE } \\
\text { Nitrate/nitrite transporter NarK2 } \\
\text { Lactose transport system permease protein LacF } \\
\text { Uric acid transporter UacT } \\
\text { Manganese ABC transporter substrate-binding lipoprotein } \\
\text { Glutamine ABC transporter permease protein GlnM } \\
\text { Phospholipid ABC transporter-binding protein MlaD }\end{array}$ \\
\hline Stress proteins & $\begin{array}{c}\text { Stress response kinase } \\
\text { General stress protein } 39,69 \\
\text { Universal stress protein } \\
\text { Persistence and stress-resistance antitoxin PasI } \\
\text { Persistence and stress-resistance toxin PasT } \\
\text { TRAP-T-associated universal stress protein TeaD } \\
\text { Acid stress protein IbaG }\end{array}$ \\
\hline Cytochromes & $\begin{array}{c}\text { Cytochrome c oxidase subunit } 2 \text { precursor } \\
\text { Cytochrome c oxidase subunit } 1 \\
\text { Cytochrome c oxidase assembly protein CtaG } \\
\text { Cytochrome c oxidase subunit } 3 \\
\text { Cytochrome bd ubiquinol oxidase subunit X } \\
\text { Cytochrome bd-I ubiquinol oxidase subunit } 2 \\
\text { Cytochrome bd ubiquinol oxidase subunit } 1 \\
\text { Gluconate 2-dehydrogenase cytochrome c subunit precursor }\end{array}$ \\
\hline
\end{tabular}


Table 1. Cont.

\begin{tabular}{c} 
Gategory Homologue \\
\hline Cytochrome c4 precursor \\
Cytochrome b561 \\
Cuccinate dehydrogenase cytochrome b556 subunit \\
Cytochrome c-552 precursor \\
Cytochrome c-554(548) \\
Quinone-reactive Ni/Fe-hydrogenase B-type cytochrome subunit \\
Fructose dehydrogenase cytochrome subunit precursor \\
Sulfide dehydrogenase [flavocytochrome c] flavoprotein chain precursor \\
Cytochrome bo (3) ubiquinol oxidase subunit 4 \\
Cytochrome bo (3) ubiquinol oxidase subunit 3 \\
Cytochrome bo (3) ubiquinol oxidase subunit 2 precursor \\
Cytochrome c biogenesis protein CcsA \\
Cytochrome c1 precursor \\
Cytochrome b/c1 \\
Ubiquinol-cytochrome c reductase iron-sulfur \\
Cytochrome c biogenesis protein CcsB \\
Cytochrome c-555 precursor \\
Cytochrome b556(fdo) subunit
\end{tabular}

ATM1-type heavy metal exporter Divalent metal cation transporter $\mathrm{MntH}$ ATP-dependent zinc metalloprotease FtsH Metal-dependent hydrolase YcfH, YjjV Metallo-beta-lactamase type 2 Metal chaperone YciC Metallo-hydrolase Yyc Metalloprotease PmbA High-affinity nickel transport protein Nickel and cobalt resistance protein $\mathrm{CnrA}$ Nickel-binding periplasmic protein Magnesium and cobalt efflux protein CorC

Metal resistance proteins Cobalt-zinc-cadmium resistance protein $\mathrm{CzcA}, \mathrm{CzcC}, \mathrm{CzcB}$ Cobalt/magnesium transport protein CorA Copper resistance protein $\mathrm{C}$ precursor Copper-exporting P-type ATPase A Copper homeostasis protein CutC Arsenical resistance operon repressor Arsenical-resistance protein Acr3 Manganese $\mathrm{ABC}$ transporter substrate-binding lipoprotein Manganese transport system membrane protein MntB

ATP-dependent zinc metalloprotease FtsH

Zinc-type alcohol dehydrogenase-like protein Zinc uptake regulation protein

Zinc import ATP-binding protein ZnuC

High-affinity zinc uptake system membrane protein ZnuB Zinc transport protein ZntB Cadmium-transporting ATPase

Multidrug resistance protein MdtH, MdtE, MdtC, NorM, stp Multidrug export protein EmrB, EmrA

Drug resistance

Multidrug resistance outer membrane protein MdtP

Multidrug efflux pump subunit AcrB

Multidrug resistance protein 3, EmrK

Multidrug export ATP-binding/permease protein

\subsection{Comparative Proteomics Study to Analyze Response to Uranium Exposure}

Proteome profiles of Burkholderia sp. (SRS-25 and SRS-46) amended with U were compared with unamended controls at $24 \mathrm{~h}$ when maximum depletion of uranium was observed (Figure 1C). The proteomics experimental scheme is shown in Figure 5. 


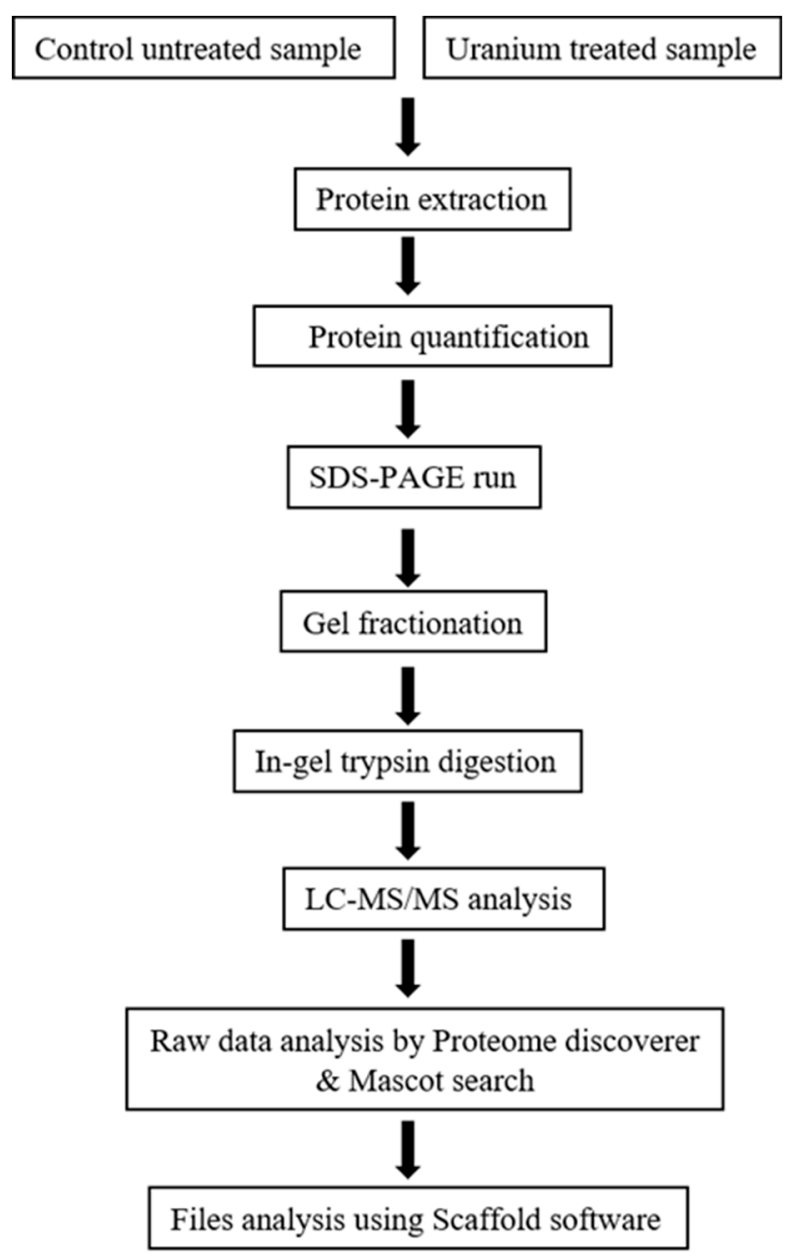

Figure 5. Shown is the proteomics workflow followed in this study.

Label free quantification (LFQs) of the proteomic data is shown in Figure S1. When the obtained proteomes were visualized using a Venn diagram, it became apparent that a total of 276 and 408 proteins were common between strains SRS-25 and SRS-46 (Figure 6). Interestingly, proteins were found in different fold ratios between unamended and $U$ amended conditions (Figure S2). Further analysis of these proteins showed that approximately 34 proteins in SRS- 25 and 52 proteins in SRS- 46 were $(\sim 2$ or $>2$-fold change) found in abundance in the presence of $U$ relative to the control. These proteins are listed (Table 2) and categorized according to their function to obtain a broader understanding on $U$ resistance mechanisms. Most of these proteins were functionally categorized into protein biosynthesis, transport, damaged DNA repair and stress response; details are presented in the following sections with a focus on $\sim 2$-fold or higher proteins expressed in $\mathrm{U}$ microcosms relative to the controls. 
A

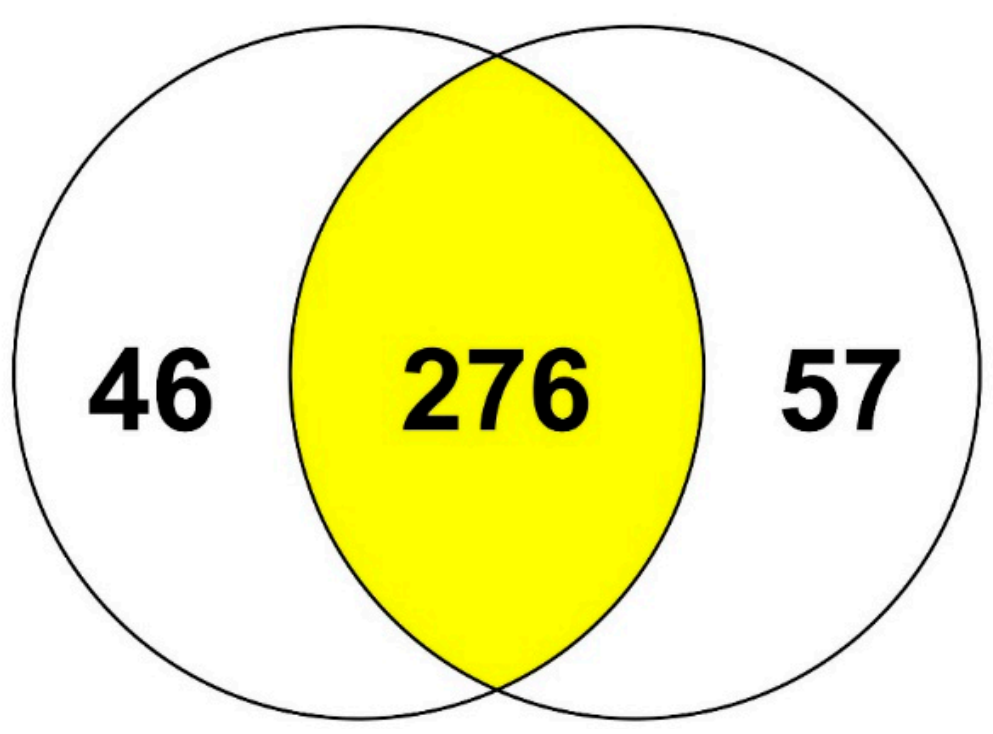

B

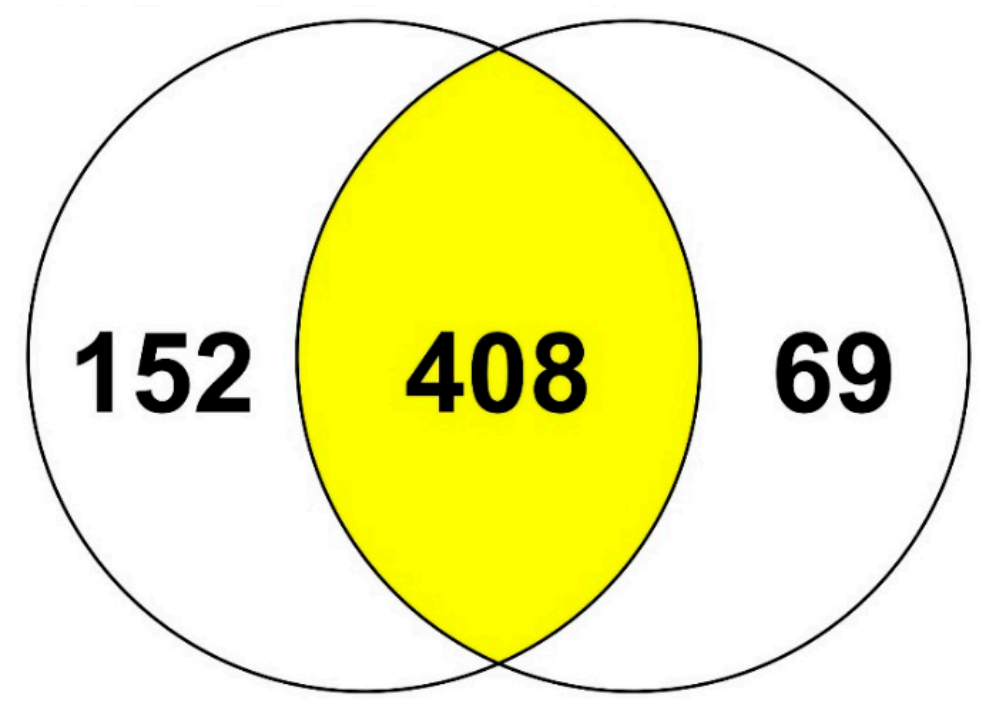

Figure 6. Proteomics data plotted as a Venn diagrams from (A) Burkholderia sp. strain SRS-25 and (B) Burkholderia sp. strain SRS-46 (B), respectively. Venn diagram sectors represent proteins expressed in control (left circle) and uranium treated (right circle). The yellow segment represents the number of commonly expressed proteins between untreated and $U$ treated samples.

Table 2. List of upregulated proteins in SRS-25 and SRS-46 strains, following exposure to uranium. Fold change represents the expression with $U$ amendment normalized to expression without $U$, respectively.

\begin{tabular}{|c|c|c|c|c|}
\hline Function & Protein & Gene & Fold Change & Strain \\
\hline \multirow{8}{*}{$\begin{array}{l}\text { Protein synthesis, } \\
\text { translation and transport }\end{array}$} & Aspartate-tRNA(Asp/Asn) ligase & aspS & 2.3 & SRS-25 \\
\hline & Alanine-tRNA ligase & alaS & 4.5 & SRS-25 \\
\hline & Elongation factor G1 & fusA1 & 2.4 & SRS-25 \\
\hline & Arginine-tRNA ligase & $\operatorname{argS}$ & 3.8 & SRS-25 \\
\hline & Glutamate-tRNA ligase & gltX & 2 & SRS-25 \\
\hline & Methionine-tRNA ligase & metG & 9.6 & SRS-25 \\
\hline & Elongation factor $\mathrm{G} 2$ & fusA2 & 2.1 & SRS-25 \\
\hline & Protein translocase subunit SecA & secA & 4.7 & SRS-25 \\
\hline
\end{tabular}


Table 2. Cont.

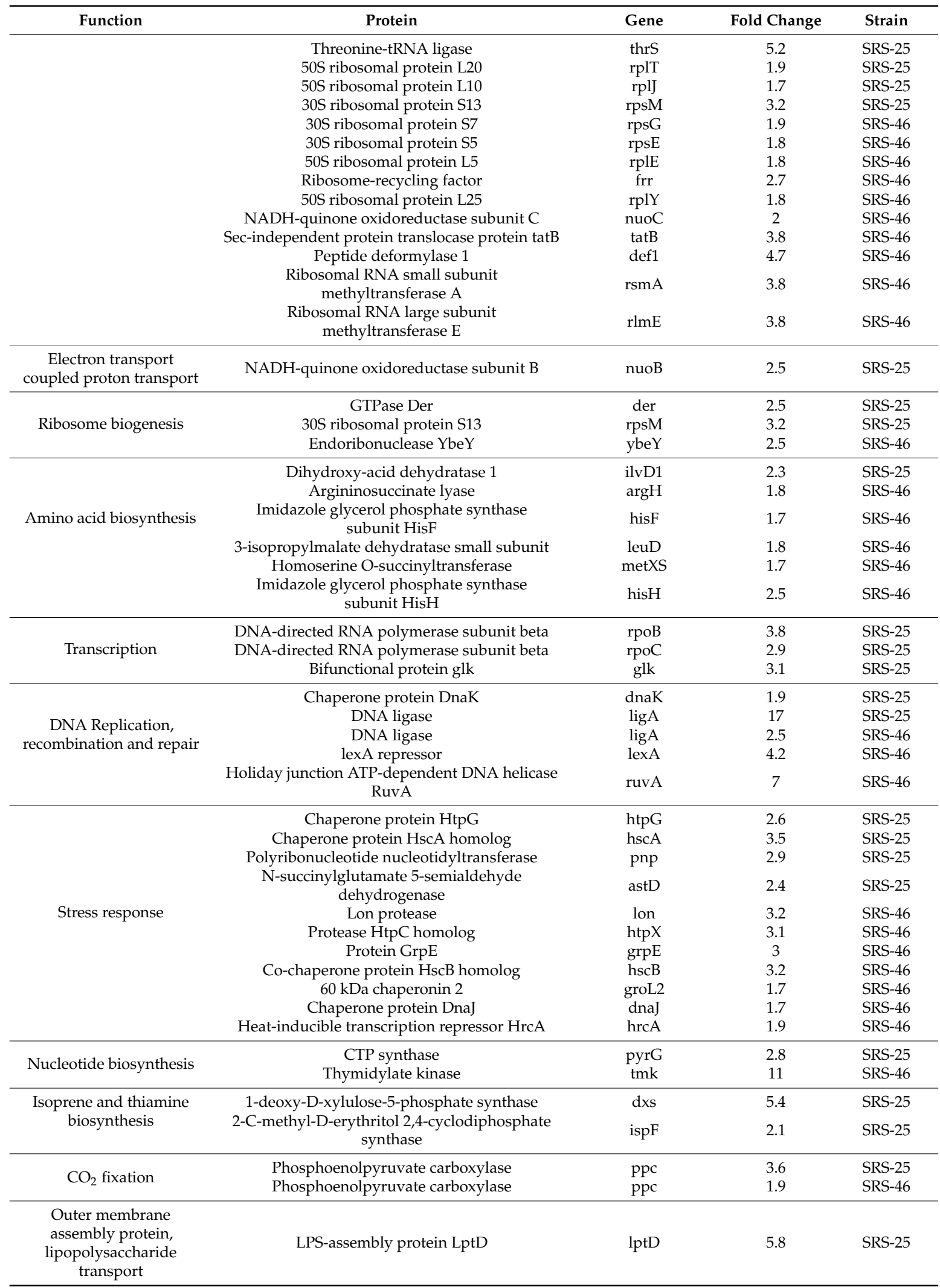


Table 2. Cont.

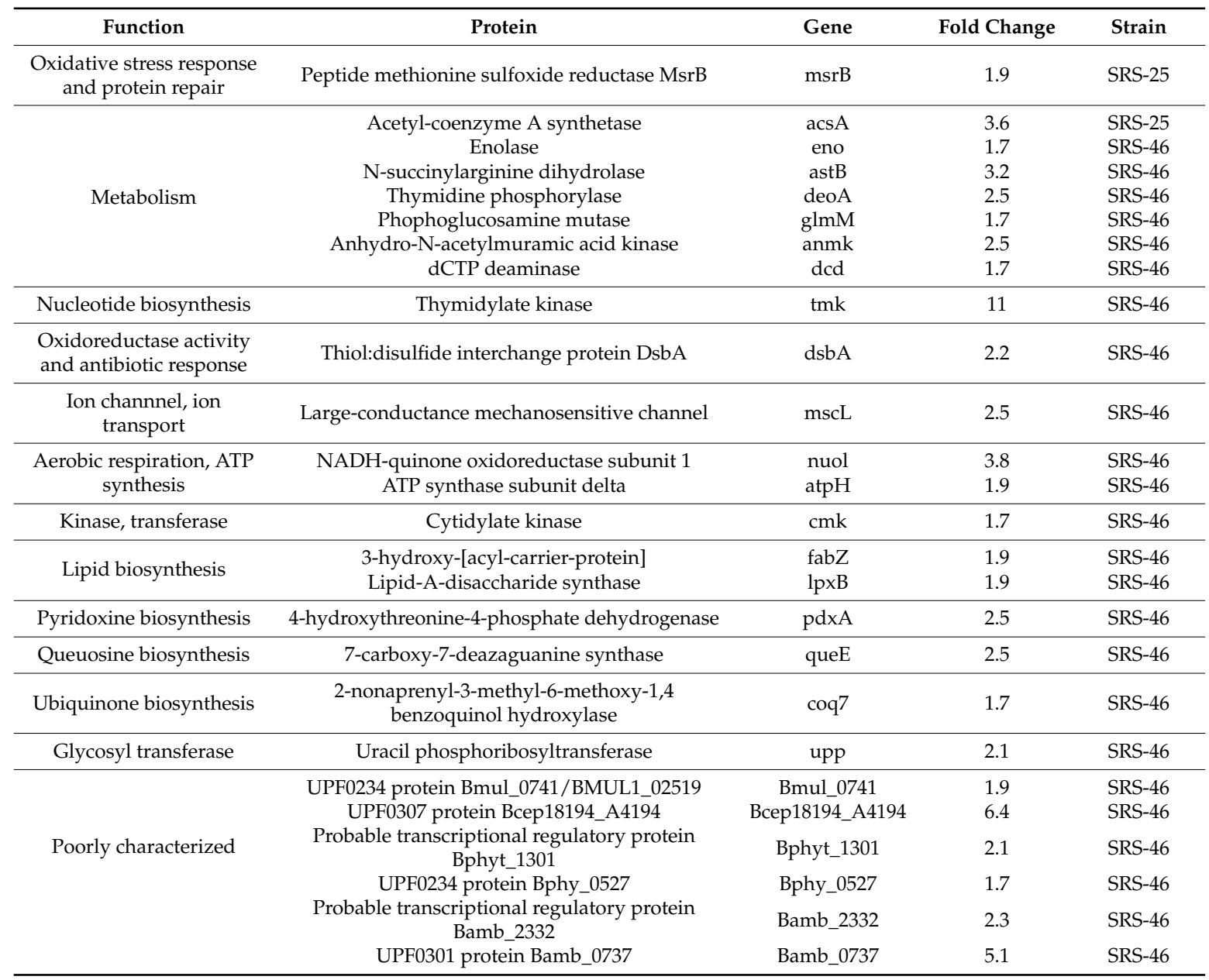

\subsection{Protein Biosynthesis and Growth}

Several proteins which are involved in biosynthesis, (for e.g., Proline-tRNA ligase, Methionine-tRNA ligase) and translation (e.g., Elongation factor G1, Translation initiation factor IF-2) were upregulated under $U$ stress, which suggests active protein synthesis as a mechanism for the bacterial cell to counter U stress. Interestingly, transporter proteins, such as protein translocase subunit SecA, which is a $\mathrm{Zn}$ binding metal protein, was also found to be upregulated in the presence of $U$ (4.7 fold higher in SRS-25). The higher abundance of proteins from this category is consitent with earlier study [36], suggesting that cells grown in the presence of $U$ were actively involved in transport, possibly of $U$. Moreover, the proteins involved in ribosome biogenesis and amino acid biosynthesis were also upregulated indicative of active cellular metabolism.

\subsection{DNA Damage, Repair and Stress Response}

It has been shown previously that U can bind to DNA and can cause DNA damage/ breakage $[37,38]$. DNA ligase plays a major role in DNA replication and DNA repair and was found highly up-regulated (17 and 2.5-fold higher in SRS-25 and 46, respectively) in both the strains (Table 2) upon exposure to $\mathrm{U}$. This likely seems a strong cellular mechanism to repair damage imposed by $\mathrm{U}$ toxicity. Additionally, Chaperone protein DnaK, involved in DNA replication and stress response, also showed 1.9 fold increase in SRS-25. Similarly, other DNA damage response proteins like Holliday junction ATP-dependent DNA helicase RuvA, and lexA repressor were also expressed in higher amount in SRS-46. The higher upregulation of these proteins suggests the possibility of DNA damage due to $\mathrm{U}$ exposure. Stress response proteins such as Chaperone protein HtpG, Chaperone protein 
HscA homolog, Co-chaperone protein HscB homolog, Lon protease etc. were also abundant in both SRS-25 and SRS-46 strains. These proteins are generally expressed in response to cellular stress to rectify misfolding of proteins [39], which was likely induced by $U$. The increased expression of peptide methionine sulfoxide reductase MsrB, having a role in oxidative stress and protein repair, further supports the above possibility. These responses are also in agreement with earlier studies [36], where $\mathrm{U}$ caused DNA damage and expression of heat labile proteins.

The expression of thymidylate kinase was also highly increased in SRS-46, which is involved in nucleotide biosynthesis; a higher expression of this protein may be due to the requirement of nulceotides during DNA repair process.

\subsection{Metabolism and ATP Synthesis}

The expression of $\mathrm{N}$-succinylarginine dihydrolase, which is involved in Arginine metabolism and also in stress response was increased (3.2 fold) in SRS-46. Other proteins like Thymidine phosphorylase involved in pyrimidine metabolic process also increased (Table 2) along with proteins involved in ATP synthesis like NADH-quinone oxidoreductase subunit 1 and ATP synthase subunit delta. This is suggestive of the cellular machinery utilizing the produced ATP for increased metabolism response or even $\mathrm{U}$ detoxification.

\subsection{Membrane Damage and Other Proteins}

The higher abundance of LPS-assembly protein LptD upon U stress is suggestive of membrane synthesis, which may have been damaged by binding or U toxicity. Similarly, increased expression of lipoproteins upon U exposure has been shown in Geobacter sulfurreducens [36]. Proteins with oxidoreducatse activity such as Thiol:disulfide interchange protein DsbA were increased (Table 2), most likely due to the cells' defense mechanism against oxidative stress. $\mathrm{A} \mathrm{CO}_{2}$ fixation enzyme Phosphoenolpyruvate caboxylase was increased, probably to balance the redox potential of cell.

\subsection{Uncharacterized Proteins}

The expression of uncharacterized proteins in SRS-46 like UPF0234 protein Bmul_0741/ BMUL1_02519, UPF0307 protein Bcep18194_A4194, UPF0301 protein Bamb_0737 was found higher in the presence of $U$. These hetherto uncharacterized proteins may be involved in conferring $U$ resistance or providing some form of protection to the bacterial cells under $U$ stress. Further research to fully characterize these proteins and establish their potential role(s) in $\mathrm{U}$ resistance is required to validate these speculations. 


\subsection{Statistical Analysis}

Proteomics data was used to evaluate differences that may have ocurred in strains 25 and 46 as a function of uranium exposure relative to the controls. Preliminary analysis plotted as heatmaps (Figure S2), which revealed that U exposure resulted in the identification of a plethora of upregulated proteins in both strains relative to the non-uranium containing microcosms. For better visualization, we then selected the top 50 proteins based on the fold-change, from either strains, plotted to show distinctions observed between controls and uranium exposure; this is shown in Figure 7A-C.

A

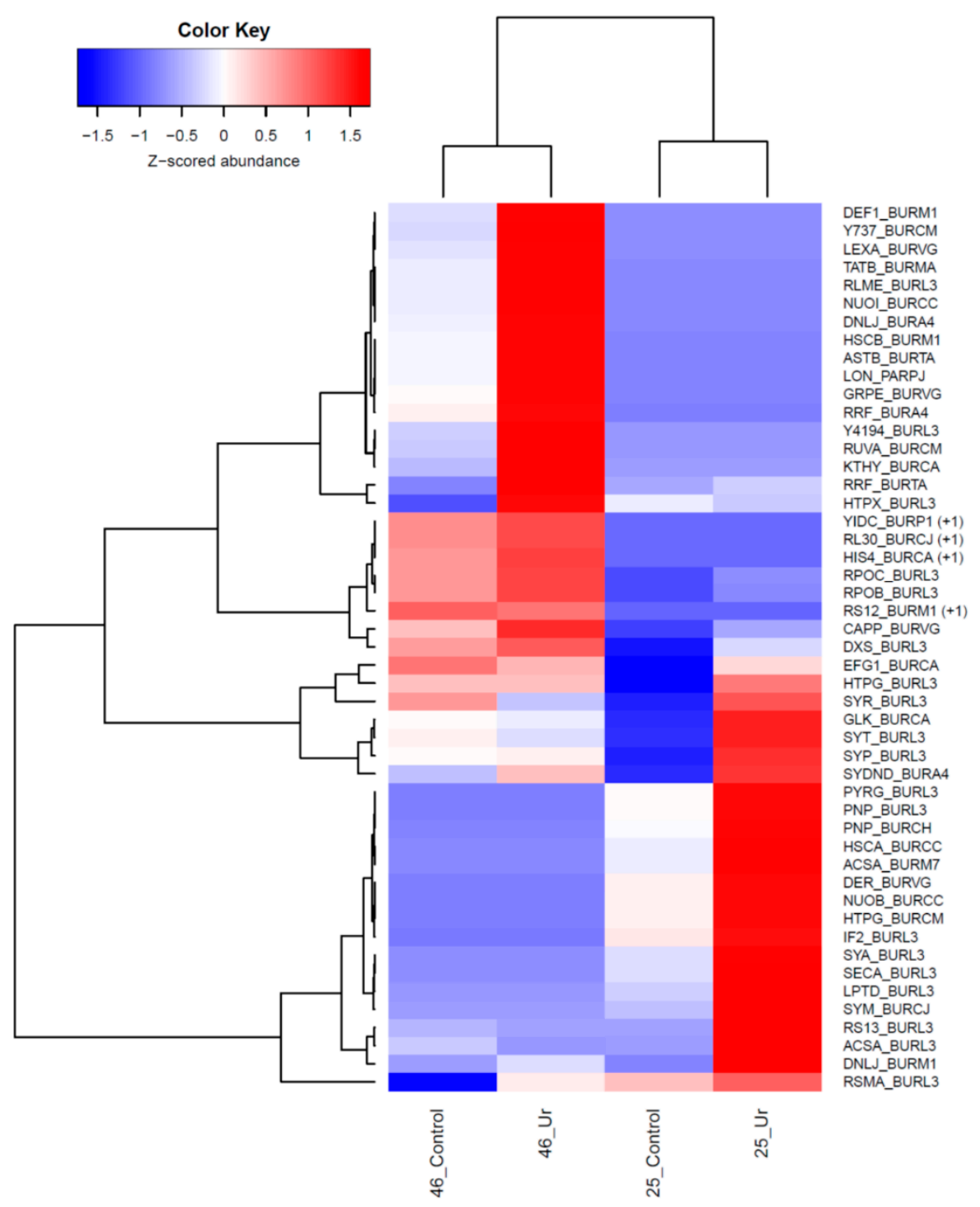

Figure 7. Cont. 
$\mathrm{B}$

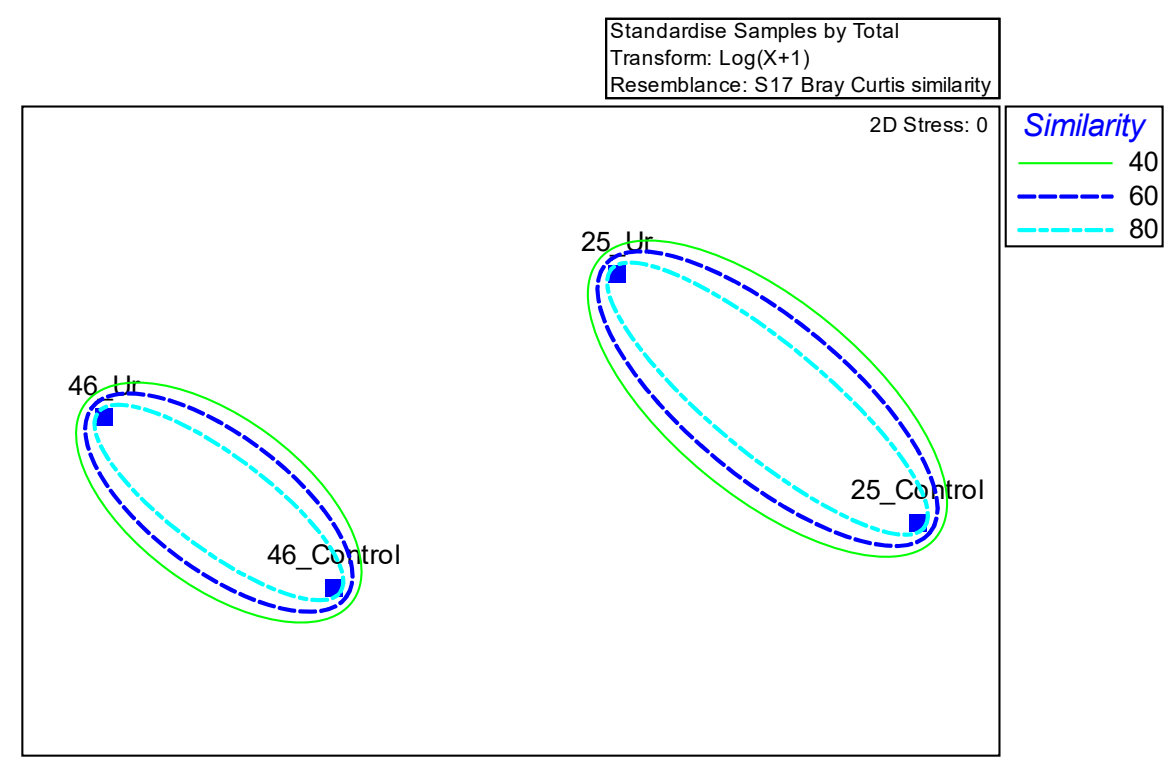

C

Group average

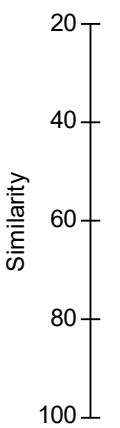

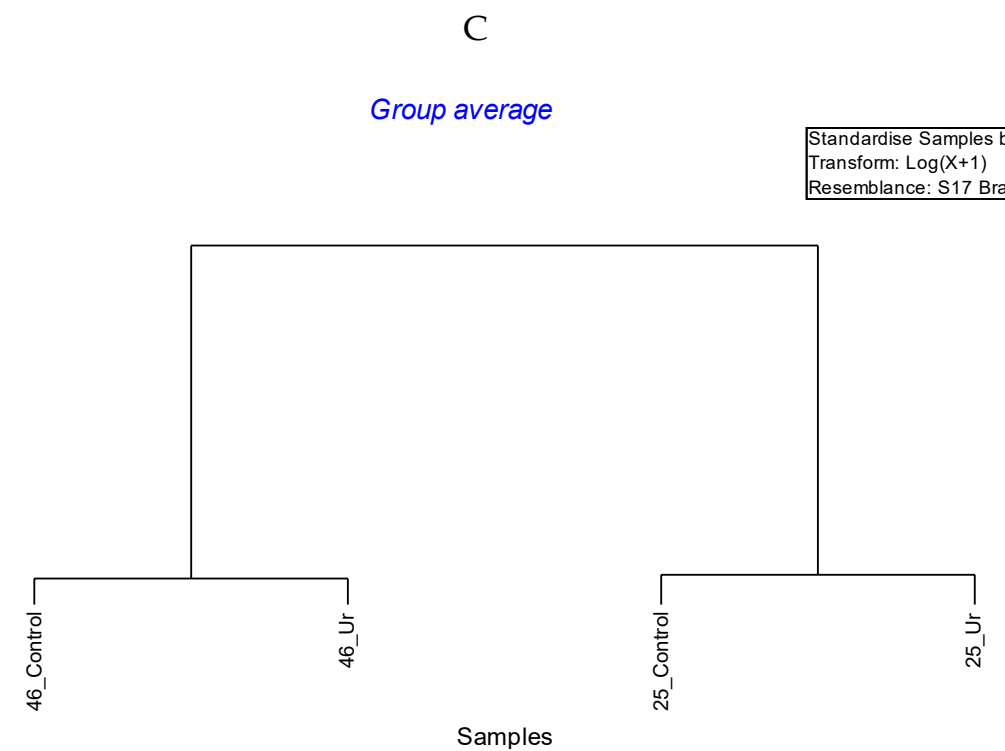

Figure 7. Shown is the heatmap obtained from Burkholderia sp. strains 25 and 46 with top 50 proteins by fold-change from either of the two strains plotted to show their distinctions observed between controls and uranium exposure (A). Gradient of fold change is shown by color code, where blue represents the lower most fold change value and red represents the highest fold change value. Parenthesis in yellow and green color represents those proteins that were identified as over-represented in strains 25 and 46; (B) Nonmetric multidimensional scaling (NMDS) ordination of all identified proteins from either strain; Bray-Curtis similarity values between are shown at the $40 \%, 60 \%$, and $80 \%$ levels; and (C) Dendrogram based cluster analysis of the NMDS of total identified proteins. Data was standardized, transformed by $\log (\mathrm{X}+1)$ and resemblance matrix was calculated prior to plotting the NMDS and dendrogram.

\section{Discussion}

The ability of bacterial strains to persist in uraniferous ecosystems has been well documented for anaerobic microbiota, which are well known to be engaged in uranium cycling processes [36]. However, the potential of aerobic microorganisms to biomineralize uranium has been largely ignored 
and hence understudied. Interestingly, Burkholderia-like microorganisms have been demonstrated to comprise a significant proportion of the total uraniferous soil microbiota at the Integrated Field-Scale Subsurface Research Challenge Site (IFRC), Oak Ridge, Tennessee [15], as well as Rifle, Colorado [16]; yet, not much is known about the cellular and molecular response(s) of Burkholderiales against $\mathrm{U}$ toxicity. In this study, Burkholderia sp. strains 25 and 46 were isolated from uraniferous soils of the Tims Branch- Steed Pond site in SRS, which is characterized by histroical contamination with heavy metals due to nuclear weapons' production activities. Micrcosoms established with these strains in the presence of externally added uranium showed rapid $U$ depletetion within $24 \mathrm{~h}$. There are at least four well-known mechanisms by which bacteria can transform and resist $U$ toxicity. These include reductive precipitation by outer membrane cytochromes, pili, or spores; surface adsorption by exopolysaccharide (EPS) or S-layers; or biomineralization of $U$ with the help of phosphatase enzymes [40,41]. A phosphatase positive response of both strains on TPMG media indicates their ability to biomineralize uranium, but this needs to be rigorously tested.

To have a better understanding of the metabolic potential possessed by the two Burkholderia strains, draft genome sequences were prepared and analyzed, which resulted in the identification of a plethora of genes related to metal resistance, transporter proteins, cytochromes and drug resistance (Table 1). The genomics analysis confirms the strong metabolic and bioremediation potential possessed by these strains that likely facilitates survival in the co-contaminated SRS soil habitat. As stated above, Burkholderia spp. has previously been shown to successfully colonize habitats characterized with extreme environmental stresses, including uraniferous niches; this study points to an arsenal of genome-enabled traits to do so successfully.

Further, which of the genome-enbled mechanisms mechanism(s) were upregulated due to uranium exposure were further probed by evaluating proteomic changes in the presence or absence of uranium stress. Note that despite predominance of Burkholderia spp., documented at several uranium contaminated environments, studies have not been performed to assess how these Proteobacterial members respond against uranium stress, which could provide critical clues on uranium bioremediation and recommendations on better stewardship of nuclear materials contaminated ecosystems can be offered. To our knowledge, there are only a few studies available, where different bacterial strains were exposed to $U$ and proteomes were analyzed $[19,20,36,42,43]$.

To address this knowledge gap, specifically in context to Burkholderia species, our proteomics-guided approach led to the identification of 276 and 408 commonly expressed proteins between strains SRS-25 and SRS-46 (Figure 6). Arguably, the number of proteins detected in this study were found to be unusually low and this occurs typically from poor sample preparation and LC discrimination. However, the raw data obtained, such as the LC control runs (Figure S1) and the number of solubilized membrane proteins (Figure S3) do not support this notion. Yet another reason that may likely have an impact on the proteome analysis presented in this study could be the use of a publicly available Burkholderia proteome database via UniProt. In the event that strains SRS-25 and SRS-46 contained large genomic deviations from the publicly available database, it may cause a significant impact on the proteome search. However, this also does not appear to be the case by taxonomic analysis of the draft genomes of strains 25 and 46 (Figure 3), which shows genome-wide affiliations of strain 25 with Burkholderia lata and strain 46 with Burkholderia multivorans, respectively. Regardless, this discrepancy can likely be addressed in our future work in which we will use translated genomes of strains SRS-25 and SRS-46 and then run proteomics comparisons. We, however, strongly believe that searching the proteomes from translated databases of environmental Burkholderia strains would have limited value because comparisons with the entire Burkholderia database will reveal better proteomic insights mainly due to rigorous annotations and functional evaluations of the known proteins from different experimental studies as opposed to using just one or two strains isolated from uraniferous soils.

Despite low protein yeilds, this study led to the identification of a set of upregulated proteins as a function of uranium exposure-34 proteins in SRS-25 and 52 in SRS-46, respectively (Table 2). 
Furthermore, statistical analysis indicated that each of the two strains possess their unique set of proteins to counteract stress and toxicity imposed by uranium, as a shared pool of proteins being expressed in both strains due to uranium exposure was not clearly evident (Figure 7). Despite the fact that both strains were isolated from the same soil and season, yet their total proteomics response against uranium toxicity seemed to be counteruntuitive, such that the proteomes of the two strains differed but not as a function of uranium alone. It may be that the Burkholderia strains 25 and 46 colonized different microniches in the soils from where they were isolated and thus, were exposed to different levels of bioavailable uranium, and hence, evolved different proteomic responses against uranium toxicity. Moreover, future protein validations will provide further evidence to completely understand why proteomes of the two Burkholderia species were statistically different with uranium not exhibiting the expected impact (Figure 7), and more importantly, identification of uranium-specific protein targets in Burkholderiales.

Regardless, upon further review, the unique 34 proteins from strain SRS-25 and 52 from SRS-46, were those that were previously shown to function in bacterial stress response, DNA repair, protein biosynthesis, and metabolism. By inference, it appeared that uranium upregulated multiple stress response pathways and heavy metal resistance functions to enable ecological and evolutionary survival in uraniferous soils. Multiple stress response pathways became functional in the two Burkholderia strains most likely due to their innate ability to resist higher concentrations of uranium, as shown in this study (Figure 1). In contrast to our study, previous proteomics studies have been performed at much lower concentrations of uranium that do not represent environmentally relevant concentrations, especially in context to the SRS soil habitat. For example, Caulobacter crescentus was exposed to $200 \mu \mathrm{M}$ or $500 \mu \mathrm{M}$ of uranyl nitrate (Yung et al. 2014); Geobacter sulfurreducens at $100 \mu \mathrm{M}$ of uranyl acetate [36]; Acidithiobacillus ferrooxidans to $0.5 \mathrm{mM}$ of uranium [42]; the nitrogen fixing strain, Anabaena, was exposed to $75 \mu \mathrm{M}$ and $200 \mu \mathrm{M}$ of uranyl carbonate [42] and Microbacterium oleivorans A9 at $10 \mu \mathrm{M}$ of uranyl nitrate [19], respectively. Notably, a recent study from our laboratory suggests that bioavailable uranium is approximately 5 to 30 times lower than the total soil uranium concentrations $(\sim 4.2 \mathrm{mM})$ that is typically been documented from the historically contaminated SRS soils [22]; thus, we plan to repeat the proteomics studies at environmentally bioavailable concentrations of uranium, results of which will further improve our basic understanding on uranium-bacterial interactions at the cellular and molecular level.

Noteworthy also, were the upregulation of previously uncharacterized proteins in SRS-46, such as the UPF0234 protein Bmul_0741/BMUL1_02519, UPF0307 protein Bcep18194_A4194, and UPF0301 protein Bamb_0737, which were higher in the presence of uranium. Other studies on Geobacter sp., Microbacterium sp., Acidithiobacillus sp., have also led to the identification of uncaracterized proteins under uranium stress [19,42], and thus, points to the lack of knowledge on the underpinnings of uranium-microbial interactions at the molecular level. It is very likely that the suite of uncharacterized proteins may also be engaged in conferring resistance or even biomineralization of uranium in Burkholderiales, which warrants further research.

In summation, this study further enhances our understanding of the multiple proteogenomic mechanisms of two newly isolated and soil-borne Burkholderia strains against uranium stress and provides for a framework for additional studies, especially at much shorter time-scales (e.g., hourly intervals post uranium exposure), and more importantly, at bioavailable and environmentally relevant concentrations of uranium, such that precise molecular mechanism(s) underpinning Burkholderia-uranium interactions and remediation can be better understood.

Supplementary Materials: The following are available online at http:/ / www.mdpi.com/2073-4409/7/12/269/s1, Figure S1: The label free quantification (LFQ) proteomics data, Figure S2: Heat maps from SRS-25 (left) and SRS-46 (right) show the of relative abundance of all the identified proteins between control and uranium amended microcosms, Figure S3: Plotted are proteins obtained from strains SRS-25 (top) and SRS-46 (bottom) with or without uranium exposure, analyzed by Scaffold software using gene ontology (GO) analysis tool.

Author Contributions: Conceptualization, A.C., O.P., A.P., R.J and R.S.; Methodology, O.P., R.J., R.S.R., and R.S.; Software, A.C., A.P., M.A., O.P., and R.S.R.; Validation, M.S., R.S.R., O.P., and R.S.; Formal Analysis, A.C., M.A., 
A.P., R.J., O.P., R.S.R., and R.S.; Investigation, A.C., M.A., A.P., R.J., O.P., R.S.R., and R.S.; Resources, A.C., and R.S.; Data Curation, A.C., M.A., A.P., and R.S.; Writing-Original Draft Preparation, A.C., A.P., J.S.; Writing-Review \& Editing, A.C., A.P., M.A., O.P., R.S., and J.S.; Visualization, A.C., M.A., A.P., O.P., and R.S.; Supervision, A.C. and R.S.; Project Administration, A.C.; Funding Acquisition, A.C.

Funding: This study was funded by the Department of Energy (DOE) Minority Serving Institution Partnership program (MSIPP) managed by the Savannah River National laboratory under SRNS contracts DE-AC09-08SR22470 (DOE subcontracts 0000217620 and 0000003889). Seaman's participation was partially supported by the Department of Energy under Award Number DE-EM0004391 to the University of Georgia Research Foundation.

Acknowledgments: We acknowledge the proteomics facility of Translational Science Laboratory, Florida State University, Tallahassee, Florida. Burkholderia strains listed are available from the culture collection housed at Chauhan's laboratory, School of the Environment, Florida Agricultural and Mechanical University, Tallahassee, FL-USA.

Conflicts of Interest: The authors declare that they have no conflict of interest.

\section{References}

1. Riley, R.G.; Zachara, J.M. Chemical Contaminants on DOE Lands and Selection of Contaminant Mixtures for Subsurface Science Research; Pacific Northwest Laboratory: Richland, WA, USA, 1992.

2. Evans, A.; Bauer, L.; Haselow, J.; Hayes, D.; Martin, H.; McDowell, W.; Pickett, J. Uranium in the Savannah River Site Environment; Westinghouse Savannah River Co.: Aiken, SC, USA, 1992.

3. Martinez, R.J.; Wu, C.H.; Beazley, M.J.; Andersen, G.L.; Conrad, M.E.; Hazen, T.C.; Taillefert, M.; Sobecky, P.A. Microbial community responses to organophosphate substrate additions in contaminated subsurface sediments. PLoS ONE 2014, 9, e100383. [CrossRef] [PubMed]

4. Newsome, L.; Morris, K.; Lloyd, J.R. The biogeochemistry and bioremediation of uranium and other priority radionuclides. Chem. Geol. 2014, 363, 164-184. [CrossRef]

5. Ye, Q. Microbial Diversity Associated with Metal- and Radionuclide-Contamination at the DOE Savannah River Site (SRS), South Carolina, USA. Ph.D. Thesis, East China Normal University, Shanghai, China, 2007.

6. Kumar, R.; Nongkhlaw, M.; Acharya, C.; Joshi, S.R. Uranium (U)-tolerant bacterial diversity from U ore deposit of Domiasiat in North-East India and its prospective utilisation in bioremediation. Microbes Environ. 2013, 28, 33-41. [CrossRef] [PubMed]

7. Kulkarni, S.; Misra, C.S.; Gupta, A.; Ballal, A.; Apte, S.K. Interaction of uranium with bacterial cell surfaces: Inferences from phosphatase-mediated uranium precipitation. Appl. Environ. Microbiol. 2016, 82, 4965-4974. [CrossRef] [PubMed]

8. Martinez, R.J.; Beazley, M.J.; Taillefert, M.; Arakaki, A.K.; Skolnick, J.; Sobecky, P.A. Aerobic uranium (VI) bioprecipitation by metal-resistant bacteria isolated from radionuclide- and metal-contaminated subsurface soils. Environ. Microbiol. 2007, 9, 3122-3133. [CrossRef] [PubMed]

9. Beazley, M.J.; Martinez, R.J.; Sobecky, P.A.; Webb, S.M.; Taillefert, M. Uranium biomineralization as a result of bacterial phosphatase activity: Insights from bacterial isolates from a contaminated subsurface. Environ. Sci. Technol. 2007, 41, 5701-5707. [CrossRef]

10. Mumtaz, S.; Streten-Joyce, C.; Parry, D.L.; McGuinness, K.A.; Lu, P.; Gibb, K.S. Fungi outcompete bacteria under increased uranium concentration in culture media. J. Environ. Radioact. 2013, 120, 39-44. [CrossRef]

11. Guo, H.; Luo, S.; Chen, L.; Xiao, X.; Xi, Q.; Wei, W.; Zeng, G.; Liu, C.; Wan, Y.; Chen, J.; et al. Bioremediation of heavy metals by growing hyperaccumulaor endophytic bacterium Bacillus sp. L14. Bioresour. Technol. 2010, 101, 8599-8605. [CrossRef]

12. Das, S.; Dash, H.R.; Chakraborty, J. Genetic basis and importance of metal resistant genes in bacteria for bioremediation of contaminated environments with toxic metal pollutants. Appl. Microbiol. Biotechnol. 2016, 100, 2967-2984. [CrossRef]

13. Pathak, A.; Chauhan, A.; Stothard, P.; Green, S.; Maienschein-Cline, M.; Jaswal, R.; Seaman, J. Genome-centric evaluation of Burkholderia sp. strain SRS-W-2-2016 resistant to high concentrations of uranium and nickel isolated from the Savannah River Site (SRS), USA. Genom. Data 2017, 12, 62-68. [CrossRef]

14. Suzuki, Y.; Banfield, J.F. Resistance to, and accumulation of, uranium by bacteria from a uraniumcontaminated site. Geomicrobiol. J. 2004, 21, 113-121. [CrossRef] 
15. North, N.N.; Dollhopf, S.L.; Petrie, L.; Istok, J.D.; Balkwill, D.L.; Kostka, J.E. Change in bacterial community structure during in situ biostimulation of subsurface sediment cocontaminated with uranium and nitrate. Appl. Environ. Microbiol. 2004, 70, 4911-4920. [CrossRef] [PubMed]

16. Koribanics, N.M.; Tuorto, S.J.; Lopez-Chiaffarelli, N.; McGuinness, L.R.; Häggblom, M.M.; Williams, K.H.; Long, P.E.; Kerkhof, L.J. Spatial distribution of an uranium-respiring betaproteobacterium at the Rifle, CO field research site. PLoS ONE 2015, 10, e0123378. [CrossRef] [PubMed]

17. Lessie, T.G.; Hendrickson, W.; Manning, B.D.; Devereux, R. Genomic complexity and plasticity of Burkholderia cepacia. FEMS Microbiol. Lett. 1996, 144, 117-128. [CrossRef] [PubMed]

18. Juhas, M.; van der Meer, J.R.; Gaillard, M.; Harding, R.M.; Hood, D.W.; Crook, D.W. Genomic islands: Tools of bacterial horizontal gene transfer and evolution. FEMS Microbiol. Rev. 2009, 33, 376-393. [CrossRef] [PubMed]

19. Gallois, N.; Alpha-Bazin, B.; Ortet, P.; Barakat, M.; Piette, L.; Long, J.; Berthomieu, C.; Armengaud, J.; Chapon, V. Proteogenomic insights into uranium tolerance of a Chernobyl's Microbacterium bacterial isolate. J. Proteom. 2018, 177, 148-157. [CrossRef] [PubMed]

20. Yung, M.C.; Ma, J.; Salemi, M.R.; Phinney, B.S.; Bowman, G.R.; Jiao, Y. Shotgun proteomic analysis unveils survival and detoxification strategies by Caulobacter crescentus during exposure to uranium, chromium, and cadmium. J. Proteome Res. 2014, 13, 1833-1847. [CrossRef] [PubMed]

21. Hu, P.; Brodie, E.L.; Suzuki, Y.; McAdams, H.H.; Andersen, G.L. Whole-genome transcriptional analysis of heavy metal stresses in Caulobacter crescentus. J. Bacteriol. 2005, 187, 8437-8449. [CrossRef] [PubMed]

22. Chauhan, A.; Pathak, A.; Jaswal, R.; Edwards, B., III; Chappell, D.; Ball, C.; Garcia-Sillas, R.; Stothard, P.; Seaman, J. Physiological and comparative genomic analysis of arthrobacter sp. SRS-W-1-2016 provides insights on niche adaptation for survival in uraniferous soils. Genes 2018, 9, 31. [CrossRef] [PubMed]

23. Riccio, M.L.; Rossolini, G.M.; Lombardi, G.; Chiesurin, A.; Satta, G. Expression cloning of different bacterial phosphatase-encoding genes by histochemical screening of genomic libraries onto an indicator medium containing phenolphthalein diphosphate and methyl green. J. Appl. Microbiol. 1997, 82, 177-185. [CrossRef] [PubMed]

24. Van Nostrand, J.D.; Khijniak, T.J.; Neely, B.; Sattar, M.A.; Sowder, A.G.; Mills, G.; Bertsch, P.M.; Morris, P.J. Reduction of nickel and uranium toxicity and enhanced trichloroethylene degradation to Burkholderia vietnamiensis PR1301 with hydroxyapatite amendment. Environ. Sci. Technol. 2007, 41, 1877-1882. [CrossRef] [PubMed]

25. Bankevich, A.; Nurk, S.; Antipov, D.; Gurevich, A.A.; Dvorkin, M.; Kulikov, A.S.; Lesin, V.M.; Nikolenko, S.I.; Pham, S.; Prjibelski, A.D.; et al. SPAdes: A new genome assembly algorithm and its applications to single-cell sequencing. J. Comput. Biol. 2012, 19, 455-477. [CrossRef] [PubMed]

26. Langmead, B.; Salzberg, S.L. Fast gapped-read alignment with Bowtie 2. Nat. Methods 2012, 9, 357-359. [CrossRef] [PubMed]

27. Grant, J.R.; Arantes, A.S.; Stothard, P. Comparing thousands of circular genomes using the CGView Comparison Tool. BMC Genom. 2012, 13. [CrossRef] [PubMed]

28. Markowitz, V.M.; Chen, I.-M.A.; Palaniappan, K.; Chu, K.; Szeto, E.; Grechkin, Y.; Ratner, A.; Jacob, B.; Huang, J.; Williams, P.; et al. IMG: The integrated microbial genomes database and comparative analysis system. Nucleic Acids Res. 2012, 40, D115-D122. [CrossRef]

29. Aziz, R.K.; Bartels, D.; Best, A.A.; DeJongh, M.; Disz, T.; Edwards, R.A.; Formsma, K.; Gerdes, S.; Glass, E.M.; Kubal, M.; et al. The RAST server: Rapid annotations using subsystems technology. BMC Genom. 2008, 9. [CrossRef]

30. Minot, S.S.; Krumm, N.; Greenfield, N.B. One codex: A sensitive and accurate data platform for genomic microbial identification. BioRxiv 2015. [CrossRef]

31. Blom, J.; Albaum, S.P.; Doppmeier, D.; Pühler, A.; Vorhölter, F.-J.; Zakrzewski, M.; Goesmann, A. EDGAR: A software framework for the comparative analysis of prokaryotic genomes. BMC Bioinform. 2009, 10, 154. [CrossRef]

32. Vizcaíno, J.A.; Csordas, A.; del-Toro, N.; Dianes, J.A.; Griss, J.; Lavidas, I.; Mayer, G.; Perez-Riverol, Y.; Reisinger, F.; Ternent, T.; et al. 2016 update of the PRIDE database and its related tools. Nucleic Acids Res. 2016, 44, D447-D456. [CrossRef]

33. Pinto-Carbó, M.; Sieber, S.; Dessein, S.; Wicker, T.; Verstraete, B.; Gademann, K.; Eberl, L.; Carlier, A. Evidence of horizontal gene transfer between obligate leaf nodule symbionts. ISME J. 2016, 10, 2092-2105. [CrossRef] 
34. Mahenthiralingam, E.; Urban, T.A.; Goldberg, J.B. The multifarious, multireplicon Burkholderia cepacia complex. Nat. Rev. Microbiol. 2005, 3, 144-156. [CrossRef] [PubMed]

35. Eberl, L.; Vandamme, P. Members of the genus burkholderia: Good and bad guys. F1000Res. $2016,5$. [CrossRef] [PubMed]

36. Orellana, R.; Hixson, K.K.; Murphy, S.; Mester, T.; Sharma, M.L.; Lipton, M.S.; Lovley, D.R. Proteome of geobacter sulfurreducens in the presence of U(VI). Microbiology 2014, 160, 2607-2617. [CrossRef] [PubMed]

37. Matsuda, E.; Nakajima, A. Effect of catechins and tannins on depleted uranium-induced DNA strand breaks. J. Radioanal. Nucl. Chem. 2012, 293, 711-714. [CrossRef]

38. Zobel, C.R.; Beer, M. Electron stains. I. Chemical studies on the interaction of DNA with uranyl salts. J. Biophys. Biochem. Cytol. 1961, 10, 335-346. [CrossRef] [PubMed]

39. Lund, P.A. Microbial molecular chaperones. Adv. Microb. Physiol. 2001, 44, 93-140. [PubMed]

40. Merroun, M.L.; Selenska-Pobell, S. Bacterial interactions with uranium: An environmental perspective. J. Contam. Hydrol. 2008, 102, 285-295. [CrossRef]

41. Morcillo, F.; González-Muñoz, M.T.; Reitz, T.; Romero-González, M.E.; Arias, J.M.; Merroun, M.L. Biosorption and biomineralization of $\mathrm{U}(\mathrm{VI})$ by the marine bacterium Idiomarina loihiensis MAH1: Effect of background electrolyte and pH. PLoS ONE 2014, 9, e91305. [CrossRef]

42. Dekker, L.; Arsène-Ploetze, F.; Santini, J.M. Comparative proteomics of Acidithiobacillus ferrooxidans grown in the presence and absence of uranium. Res. Microbiol. 2016, 167, 234-239. [CrossRef]

43. Panda, B.; Basu, B.; Acharya, C.; Rajaram, H.; Apte, S.K. Proteomic analysis reveals contrasting stress response to uranium in two nitrogen-fixing Anabaena strains, differentially tolerant to uranium. Aquat. Toxicol. 2017, 182, 205-213. [CrossRef]

(C) 2018 by the authors. Licensee MDPI, Basel, Switzerland. This article is an open access article distributed under the terms and conditions of the Creative Commons Attribution (CC BY) license (http:/ / creativecommons.org/licenses/by/4.0/). 